\title{
The use of DNA barcodes in food web construction - terrestrial and aquatic ecologists unite!
}

\begin{tabular}{|r|l|}
\hline Journal: & Genome \\
\hline Manuscript ID & gen-2015-0229.R1 \\
\hline Manuscript Type: & Review \\
\hline Date Submitted by the Author: & 05-Mar-2016 \\
\hline Keyplete List of Authors: & $\begin{array}{l}\text { Roslin, Tomas; Swedish University of Agricultural Sciences, Department of } \\
\text { Ecology; University of Helsinki, Department of Agricultural Sciences } \\
\text { Majaneva, Sanna; Linnaeus University, Department of Biology and } \\
\text { Environmental Science }\end{array}$ \\
\hline DNA barcodes, food webs, species identification, trophic links, ecological \\
\hline
\end{tabular}




\section{The use of DNA barcodes in food web construction \\ - terrestrial and aquatic ecologists unite!}

Tomas Roslin ${ }^{1,2, *} \&$ Sanna Majaneva ${ }^{3}$

${ }^{1}$ Department of Ecology, Swedish University of Agricultural Sciences, Box 7044, 75007 Uppsala, Sweden

${ }^{2}$ Spatial Foodweb Ecology Group, Department of Agricultural Sciences, PO Box 27, (Latokartanonkaari 5), FI-00014 University of Helsinki, Finland

${ }^{3}$ Centre for Ecology and Evolution in Microbial model Systems (EEMiS), Department of Biology and Environmental Science, Linnaeus University, 39182 Kalmar, Sweden

* Corresponding author:

Tomas Roslin, Department of Ecology, Swedish University of Agricultural Sciences, Box 7044, 75007

Uppsala, Sweden. Phone +358 40 5958098, email tomas.roslin@helsinki.fi 


\section{Abstract}

By depicting who eats whom, food webs offer descriptions of how groupings in nature (typically species or populations) are linked to each other. For asking questions on how food webs are built and work, we need descriptions of food webs at different levels of resolution. DNA techniques provide opportunities for highlyresolved webs. In this paper, we offer an exposé of how DNA-based techniques, and DNA barcodes in particular, have recently been used to construct food web structure in both terrestrial and aquatic systems. We highlight how such techniques can be applied to simultaneously improve the taxonomic resolution of the nodes of the web (i.e. the species), and the links between them (i.e. who eats whom). We end by proposing how DNA barcodes and DNA information may allow new approaches to the construction of larger interaction webs, and overcome some hurdles to achieving adequate sample size. Most importantly, we propose that the joint adoption and development of these techniques may serve to unite approaches to food web studies in aquatic and terrestrial systems - revealing the extent to which food webs in these environments are structured similarly or differently from each other, and how they are linked by dispersal.

Key words: DNA barcodes, food webs, species delimitation, species identification, trophic links, ecological networks 


\section{Introduction}

\subsection{Food webs as the defining objects of community ecology}

A food web is the pattern of flows of energy and materials among organisms that results when some organisms eat or consume other living organisms or their parts (Cohen et al. 1993). Food webs have been described as the defining objects of community ecology (Kitching 2004) - since if we want to understand fundamental issues such as i) the extent to which populations of different taxa depend on each other, and how a change in the abundance of one species is likely to reflect into a change in the abundance of another (Polis and Winemiller 1996), ii) how the extinction of one species may result in the extinction of another (Dunne et al. 2002; Byrnes et al. 2007; Srinivasan et al. 2007; Pearse and Altermatt 2013; Berg et al. 2015), iii) how new species may infiltrate community structure and functioning (e.g. Henneman and Memmott 2001; Sheppard et al. 2004; Byrnes et al. 2007) or iv) how community organization varies between different parts of the world (Lewinsohn and Roslin 2008; Forister et al. 2015), among different feeding guilds (van Veen et al. 2008; Novotny et al. 2010) or with different levels of environmental change (Tylianakis et al. 2007, 2008; Tylianakis and Binzer 2014; Kaartinen and Roslin 2011), then we most certainly need to know who feeds on whom. Likewise, if we are interested in restoring a once-disturbed habitat, then we should be asking whether we can restore not only what species are there, but also how they interact with each other (Montoya et al. 2012). Again, food webs capture these features of interest (McCann 2007; Memmott 2009; Thompson et al. 2012).

Yet, how food webs are structured is also informative of patterns and processes occurring over longer time spans. By comparing food web structure to phylogenetic signal, we may explore how interacting species coevolve (Nyman et al. 2007; Vazquez et al. 2009; Rafferty and Ives 2013; Nyman et al. 2015; Fontaine and Thébault 2015). As another line of investigation, comparisons of food webs along sites of different glacial or geological history will help us understand the rules for how communities disassemble and reassemble over time (Stone et al. 2012). 


\subsection{Food web structure is affected by resolution}

In constructing trophic interactions, identifying the individual players (nodes) and describing their diet offers a start - as these sets of interactions are the building blocks (modules) of which larger webs are built (Fig. 1). Nonetheless, it is from the structure of the larger network of feeding interactions that we can infer the full coupling among taxa. Recent advances in network research have revealed the impact of structure on dynamics. Interestingly, it seems that the level to which species are woven together in the web may have different impacts on the stability of networks of antagonistic (feeding) interactions, and networks of mutualistic interactions (such as networks of plants versus seed dispersers or pollinators). In the former, stability is enhanced by compartmentalized and sparsely connected architectures, whereas in the latter, stability is enhanced by the opposite features (Thebault and Fontaine 2010; Stouffer and Bascompte 2011). Even weak links (i.e. interactions occurring with a low frequency) may have an important impact on network stability (McCann et al. 1998; Rooney and McCann 2012) - thus emphasizing the need for resolving all types of links (cf. Fig. 1).

In this context, different questions on how food webs are built and how they work will call for the construction of food webs of different type and resolution (cf. Cohen et al. 1993). For questions regarding general patterns of e.g. carbon, nutrient or energy flows between different parts of the web, a rough resolution into broad groupings has oftentimes been found sufficient (from Elton 1923 to Christensen and Pauly 1992; Legagneux et al. 2012). For questions on how webs are partitioned into different trophic levels, and how food chain length varies with the environment, we may take different approaches - from using general methods for scoring the trophic level of species in each system (Post et al. 2000; Post 2002; Post and Takimoto 2007) to using species-level resolution (Roslin et al. 2013). For questions on general structure and topology, how taxa connect with each other, and how they may rewire with the loss of some taxa, a practical and widely-adopted approach is currently to pool taxa presumed to share the same set of predators and prey into "trophic species" (Briand and Cohen 1984; Williams and Martinez 2000; Staniczenko et al. 2010; Majaneva 2014). Indeed, consumers may not perceive their resources in the same way that we do (e.g., filter feeders may graze indiscriminately on anything within a given size range). Overall, the method of choice is 
thus determined by the application, and even the criteria for what consists "adequate" resolution are often hard to agree on (Cohen et al. 1993).

What is important to note is that many descriptors of food web structure will vary dramatically with resolution whereas others do less so (e.g, Martinez 1991, 1993a, 1994). As a crude example, we may consider the connectance of a web - i.e. the fraction of all possible interactions that could occur which is actually observed to occur. In the simplest possible web of just a few predator taxa and a few prey, connectance will increase with decreasing resolution, and approach unity when all predator taxa are pooled into a single functional predator taxon and all prey taxa are pooled into a single functional prey taxon (for empirical effects of resolution on perceived connectance metrics, see Box 1). Likewise, individual links in a network (Fig. 1) will appear stronger the more individual species are summed into each. Overall, it has demonstrated that if the species or the links between them are left unresolved (or only partially resolved), then many descriptor of biodiversity, food chain length, specialization or regulation of energy flow inferred from the web will be conditional on the level to which actual blocks are confounded or smudged into “functional units” (see already Paine 1988; Martinez 1991; Martinez 1993a).

Overall, we should thus be aware that our choice of resolution may affect our perception of food web topology, that its impact will vary with the metric chosen - and thus, that different applications call for different approaches. In their classical treatise on "Improving food webs", Cohen et al. (1993, p. 253) offer a practical word of advice: that "the kinds of organisms in a food web should be reported by using units of observation that are as refined as possible. Aggregating units of observation for subsequent analysis is easy, whereas disaggregating them is often impossible”. In some cases, we should also be particularly determined in aiming for the highest end of resolution: in particular when asking questions on population-level dynamics, including the potential for indirect interactions such as apparent competition or apparent mutualism (Müller et al 1999; Morris et al. 2004, 2005; van Veen et al. 2006; Tack et al. 2011), or questions on coevolution and phylogenetic structuring (Nyman et al. 2007; Vazquez et al. 2009; Rafferty and Ives 2013; Nyman et al. 2015; Fontaine and Thébault 2015). Composite taxa may not share the same population dynamics, let alone the same evolutionary trajectories. 
Today, theory on how food webs are structured and function is advancing fast (e.g. Rooney and McCann 2012; Thompson et al. 2015; Layman et al. 2015; Hastings et al. 2016). While most of this theory is intended to be general, several rifts have emerged within the wider field. In particular, there seems to be strong dichotomy between terrestrial and aquatic studies. Most studies tend to focus on one or the other habitat, and workshops and meetings are oftentimes attended by enthusiasts of only a given realm (but see Symondson and Harwood 2014 for an excellent exception). As another zone of fissure, empirical data are arguably lagging behind theoretical advances. Very much of what we know - or think we know - about food web structure in terrestrial versus aquatic environments has been built on a relatively few model systems. For aquatic systems, core data on a set of "highly-resolved" (cf. Fig. 2B) webs has produced an astonishing wealth of papers (from Cohen 1989 to e.g.. Baird et al. 1989; Huxham et al. 1996; Havens 1992, 2002; Dunne et al. 2002, 2004; Allesina and Pascual 2009; Staniczenko et al. 2010; Hechinger et al. 2011; Mouritsen et al. 2011; Thieltges et al. 2011; Zander et al. 2011; Dunne et al. 2013; Morlon et al. 2014). For terrestrial food webs, host-parasitoid webs have been popular targets of investigation, mainly due to their perceived ease of reconstruction (for reviews, see van Veen et al. 2006; Morris et al. 2014; Hrček and Godfray 2015). Other types, such as plant-seed predator webs are now accumulating rapidly, offering valuable points of comparison (e.g. Carnicer et al. 2009; Evans et al. 2011; Albrecht et al. 2013). A third type of webs, i.e. plant-pollinators webs, are currently at the focus of particularly intensive investigation (e.g. Schleuning et al. 2012; Orford et al. 2015). While they do include an element of trophic interactions (in the form of nectar and/or pollen feeding), their population-level consequences differ fundamentally from those of predator-prey interactions. Thus, we will here refrain from including them in our survey of food webs "sensu stricto" (but see Perspectives, below).

\subsection{Problems encountered in reconstructing food web structure}

Importantly, even for well-studied model systems, current findings may be partly affected by the methods used to reconstruct them. As five specific sources of concern, patterns to date may bear marks of the methods used to identify the nodes, to identify the links, to quantify the links, the sample sizes achieved in doing so, 
and the delimitation of the studied web from the surrounding network of ecological interactions (Fig. 2). Of these issues, the first four may be of particular concern to questions addressing web topology and its consequences.

First, the nodes (cf. Fig. 1) of the webs are typically poorly resolved. For most model webs in both aquatic and terrestrial systems, the nodes have been identified by morphological criteria, even in cases where taxa (or developmental stages of taxa) are hard to identify (Fig. 2A). Thus, extant food webs will likely include mixes of "good" and cryptic species, causing some confusion in perceived network structure.

Second, the links are usually poorly resolved, and established by techniques which are hard to repeat. For many webs, link structure has been inferred from a mixed set of observations, expert opinion, feeding trials or just patterns of co-occurrence (Fig. 2B; see references in paragraph above). Interaction strength is often unquantified (from Summerhayes and Elton 1923 through Cohen et al. 1990 to Wirta et al. 2015), inferred from sometimes limited and always laborious observations of direct attacks (Carnicer et al. 2009) or through methods with an only indirect link to realized predation and consumption rates (Frost 1972; Nyffeler 1999; Diehl et al. 2013; Majaneva et al. 2014).

Third, different links are often differentially detectable, causing biases in link structure and quantification (Fig. 2C). As examples from the host-parasitoid webs so popular in terrestrial food web research, some species of parasitoids may be harder to rear than others, thus causing them to be potentially underrepresented in the food web. Also, because different species of parasitoid attack the host at different stages, the time at which the hosts are collected for rearing may influence the spectrum and relative abundances of the species recorded (Van Veen et al. 2009). Compounding these problems are the high mortality rates typical of rearings (Hrček et al. 2011). In brief, the majority of host individuals reared will die without us knowing what killed them. From the aquatic side, a case in point is the differential detectability of small, homogenous and soft versus hard-bodied nodes (such as phytoplankton and gelatinous zooplankton as compared to crustaceans with a hard exoskeleton), which hampers the detection of link structures. 
Fourth, sample size is limited and oftentimes inadequate for establishing actual web structure. As a mental exercise, it is quite sobering to realize just how many interactions one will need to inspect to encounter most interactions within a community of even mediocre species richness (Fig. 2D): as the number of potential interactions among a set of S species increases as $\mathrm{S}^{2}$, the challenges involved will easily become prohibitive. Indeed, sampling biases have been identified as some of the main obstacles to reliable food web reconstructions and comparisons (Goldwasser and Roughgarden 1997; Morris et al. 2014; but cf. BanašekRichter et al. 2004, Blüthgen et al. 2006; see also Fort et al. 2016).

Fifth, current studies of food webs are typically confined to subsets of the larger web as amenable to specific techniques. While we know that species are tied into versatile networks of ecologic interactions, we often focus on limited modules while (often per necessity) neglecting their wider setting (Fig. 2E). Even within the food web targeted, some taxa involved are simply too secretive to ever be seen eating each other (cf. Clare et al. 2014a, 2014b, 2014c; Wirta et al. 2014), or too fragile or otherwise difficult to handle (such as gelatinous zooplankton in aquatic webs: Arai 2005; Majaneva 2014 and references therein) to be comprehensively examined. Thus, we tend to end up with describing a subset of interactions cut out of their larger context. For some questions, such subsets may offer a good approximation - and it is evident that a majority of advances in food web ecology to date are based on theory and empirical evidence which uses these sub-webs. Yet, that a description of a smaller part of the web will capture its key features and is also up-scalable to larger proportions of the web remains a strong assumption, and one which we will want to continue testing empirically.

\subsection{DNA-based techniques as new tools for detail}

For tackling each of the complications outlined above, DNA-based techniques, and DNA barcodes in particular, offer novel alternatives (Fig. 2; see Kress 2015; Toju 2015). In this paper, we offer a brief exposé of recent, DNA-based approaches to adding detail to food web structure in both terrestrial and aquatic systems. In doing so, we explicitly note that DNA-based tools offer no magic bullets, but a tool among others- and may also be combined with other approaches. For brevity, we will refrain from covering pre- 
extant tools in our tool box. Yet, given our explicit focus on the detail and resolution offered by DNA-based techniques, we hasten to stress the type of detail that they contribute, i.e. a snapshot of mostly local, presentday interactions. In this aspect, they differ from many biomarker techniques (e.g., stable isotopes, fatty acids, contaminants), which offer coarser but more integrated averages of food web structure across space and time (e.g. Phillips and Eldridge 2006; Belivanov and Hambäck 2015). Thus, the latter type of methods may play an important role in understanding e.g. major energy flows, and also complement DNA-based techniques in revealing the specific origin of different prey types, even within single taxa (e.g. Carreon-Martinez and Heath 2010; Soininen et al. 2014).

In specifying our own contribution, we also note several recent overviews of the components of molecularlybased community analyses. These entries cover the technical challenges and bioinformatics decisions involved in turning from DNA barcoding single individuals to metabarcoding biological communities (Cristescu 2014; Clare et al. 2016), the rise of modern molecular dietary analysis (Symondson 2002; Furlong 2015), recommendations for best practices in diet analyses (King et al. 2008), and comparisons of specific molecular techniques for reconstructing trophic interactions (Razgour et al. 2011; Pompanon et al. 2012; Clare 2014; Toju 2015; Evans et al. 2016). Rather than repeating what has been said better before, we thus bypass these steps and explicitly focus on a fundamental, conceptual issue: how barcode-based techniques in a broad sense can be applied to improve our understanding of how food webs are actually structured - to resolve both the nodes of the web and the links between them. We end by turning our eyes to the future, proposing how DNA barcodes, and more generally DNA information, may contribute to overcoming current challenges to food web research: to quantifying the links between nodes, to pitching trophic interactions in their larger context, and to circumventing obstacles to achieving adequate sample size.

In our exposé, we have - per necessity - focused on the macroscopic, eukaryotic part of food webs, omitting most links to microbes (cf. Mostajir et al. 2015). While this choice was explicitly based on our own biased experience, and our intent to keep the length of our contribution within reasonable limits, we emphasize a simple fact: microbial-based food webs, and links between the macroscopic and microscopic parts of food 
webs, are probably the fields where molecular techniques may currently be bringing some of the most important new insights (cf. Furman et al. 2015).

\section{Terrestrial studies}

\subsection{Clarifying the nodes of terrestrial food webs}

The first aspect of food web structure that DNA barcodes may help us clarify is simply in delimiting the nodes (Fig. 1). Some of the first high-profile studies demonstrating the utility of DNA barcodes in species delimitation were explicitly aimed at establishing the identity of species within food web modules. Targeting one of the most thoroughly studied tropical insect communities in the world - that of Area de Conservación Guanacaste, northwestern Costa Rica - Hebert et al. (2004), followed by Smith et al. (2006, 2007), were able to clarify species limits at the level of both herbivores and their parasitoids. At both trophic levels, the added resolution offered by DNA barcodes revealed species thought to be generalists to actually consist of multiple, cryptic species, each with their more restricted diet specificity (i.e. each connected to the surrounding web by a lower set of links; Fig. 1). At the level of herbivores, Hebert et al. (2004) suggested that Astraptes fulgerator, a species of skipper butterflies (Lepidoptera: Hesperiidae) previously thought to be a single species as based on similar adults, was actually composed of some ten species with mostly distinctive caterpillars, as mostly feeding on different food plants. While the exact number of good species hiding within A. fulgerator has later been challenged, even the more critical studies still put this number at well above one and at a minimum of three (Brower 2006). This is thus an encouraging indication that when applied to food webs, DNA barcodes might serve to clarify the nodes of the web - and at the same time, change our view on how they are linked to each other (cf. Fig. 1): in one sweep, the plant-caterpillar module changed from a generalist species linked to wide set of host plants to a set of specialists for the most part linked to their own host plants. What was even more striking, the same pattern was repeated at the next trophic level. Here, fly parasitoids (Diptera: Tachinidae) of the herbivores thought to be generalists turned out to be composed of cryptic species, again with their more restricted set of links. When DNA barcodes 
were developed for three species of genus Belvosia thought to be generalists, they consisted of 15 cryptic specialists (Smith et al. 2006). A similar pattern was observed among a larger set of 16 presumed generalists, which encompassed a full 73 species as indicated by the molecular data (Smith et al. 2007). Of the original 16 morphospecies, some were indeed true generalists, whereas others consisted of a mix of generalist and specialist species (Smith et al. 2007).

DNA barcodes have caused similar redefinition of node limits in temperate food webs, too. In North America, parasitoids of the spruce budworm (genus Choristoneura in Lepidoptera: Tortricidae) were thought to be polyphagous generalists. With the application of DNA barcodes, these taxa have been shown to consist of morphologically indistinguishable (or hardly distinguishable) host specialists (Smith et al. 2011). Just how frequent the problems with node delimitation may be - even in food webs reconstructed within well-known faunas - is shown by a study by Kaartinen et al. (2010). When the species identifications of the higher trophic level in a bipartite (i.e. two-layer) food web consisting of leaf miners, galls and their natural enemies (parasitoids and inquilines) was rechecked by DNA barcoding, 31\% of re-examined parasitoids were attributed to another species, and $10 \%$ of parasitoid individuals were found to be misidentified - despite the fact that identification had been informed by the best taxonomic authorities and authors of current identification keys. For one group of parasites (inquiline gall wasps of genus Synergus), morphology-based species limits actually bore very little resemblance to those uncovered by DNA barcodes (Kaartinen et al. 2010; see also Ács et al. 2010).

Taken together, the patterns examined above demonstrate just how vague node limits may be in morphologybased food webs. Nonetheless, they so far offer debatable support for the conjecture of Clare (2014) that molecular methods would typically expose parasites as being more specialized than previously thought. In the end, this may well prove to be so, but the data just are not here yet: in the Costa Rican food web, DNA barcodes resolved both specialists and generalists among cryptic species (Smith et al. 2006, 2007). In the tropical forest of Papua New Guinea, it refined previous expectations regarding host specificity in different directions for different guilds and taxa (Hrček et al. 2013). In the study system of Kaartinen et al. (2010), molecularly-informed species delimitation did shift species designations (see above), but only moderately 
affected our perception of food web structure: most metrics related to specialization changed very little with the specification of node limits. In others words, the correctly-defined nodes showed properties similar to those of the original nodes. For the case of the spruce budworm, the connectance of the web was indeed reduced when taxonomic resolution was improved by molecular information (Smith et al. 2011) - but in a study of plant-leaf miner- parasitoid interactions, a network constructed using a molecular approach had a higher number of species, links, and links per species than a morphologically-based network (Derocles et al. 2015). And when Wirta et al. (2014) probed an arctic host-parasitoid food web by multiple molecular methods, they actually found a much higher number of links per species when adding molecular resolution (Box 1). Thus, at present it seems better established that molecular methods will typically refine our perception of node limits than that these adjustments would, on average, impact link numbers per species (also called "species degree") in any particular direction.

\subsection{Clarifying the links of terrestrial food webs}

Moving from studies clarifying the outlines of the nodes (and thereby indirectly affecting link structure associated with each node) to studies directly targeting the links between them, an increasing stream of papers have recently applied molecular tools to describing the diet of insectivore mammals, spiders, birds, and many more taxa (reviewed in Symondson 2002; Pompanon et al. 2012). A specific methodological challenge emerges for generalist insectivores where individual gut contents may contain many different prey items (with solutions offered by e.g. Pinol et al. 2014; Kruger et al. 2014; Paula et al. 2015, Vesterinen et al. 2013, 2016). When it comes to uncovering who feeds on whom, DNA-based techniques offer a clear-cut advantage: the potential for studying feeding relations among species too small (such as soil fauna; Digel et al. 2014), too secretive (e.g., bats: Clare 2009; Clare et al. 2014a, 2014b, 2014c; Emrich et al. 2014; Vesterinen et al. 2013, 2016; lemmings: Soininen et al. 2009), or too wide-roaming (Valentini et al. 2009) for their feeding habits to be followed by direct means. Targeting links among host-parasitoid species hard to distinguish in a region hard to access - the tropical rainforest of Papua New Guinea - Hrček et al. (2011) were able to detect 93 previously unknown trophic links between 37 host species from Lepidoptera and 46 parasitoid species from Hymenoptera and Diptera. They even detected specialized links among individual 
parasitoid taxa and individual species within a pair of Choreutis (Lepidotera: Choreutidae) species differing in neither caterpillar morphology nor ecology.

\subsection{Resolving substructuring within terrestrial species and populations}

By providing high resolution, DNA barcodes may contribute to resolving not only links between species, but also important sub-structuring within species and populations (cf. Cohen et al. 1993). In a limited number of species, DNA-based studies have resolved shifts in diet with life stage. In e.g. holometabolous insects, species will regularly shift between different feeding modes and trophic guilds in different life stages (Pocock et al. 2012). Nonetheless, developmental diet shifts will also occur in some vertebrates. Molecular studies targeting smooth snakes (Coronella austriaca) have revealed juveniles to be more dependent on reptile prey, whereas adults feed more on mammals (Brown et al. 2014). At the population level, a study by Lavandero and Tylianakis (2013) resolved genotypic interaction networks among individuals of a single specialized parasitoid species and its aphid host along a climatic gradient. Genetically similar parasitoids became more likely to attack genetically similar hosts in warmer sites, showing how the environment may affect interaction networks within single species pairs. Each of these studies adds to the details of food web structure, and highlight the need for understanding dynamic shifts in trophic links involving even the same species.

\subsection{Reconstructing larger modules within terrestrial webs}

Where most molecular studies target single predators or a few species only, a small but growing number of studies have developed molecular tools to resolve smaller and larger modules within food webs, from plantherbivore interactions (Staudacher et al. 2011; Wallinger et al. 2012; Garcia-Robledo et al. 2013a, 2013b; Kitson et al. 2013; Kajtoch et al. 2015) to plant-leaf miner-parasitoid networks (Derocles et al. 2015). The food webs of soils offer a particular challenge - and particular scope for new insights - as species diversity is relatively high, trophic relations complex, and direct feeding interactions oftentimes impossible to observe. Here, a wealth of studies have applied DNA barcodes - or taxon-specific amplicons targeting sequence 
variation within the barcoding region (e.g. Eitzinger et al. 2013; Heidemann et al. 2014; Brose and Scheu 2014; Digel et al. 2014). Tentative evidence from food web reconstruction encompassing molecular gut content analysis identify soil food webs as being highly complex, and characterized by high link densities (Digel et al. 2014).

As an exciting development, molecular analyses are being increasingly adopted to address applied questions on terrestrial food webs. Derocles et al. (2014) used sequences of the rRNA 16S gene to assess the level to which aphid and parasitoid food webs share members across cultivated and uncultivated habitats. The wellresolved molecular network proved highly compartmentalized and suggested that parasitoid sharing is relatively rare between aphids of different parts of the landscape. Thus, field margins may actually be more modest sources of these biocontrol agents than previously thought. In another study, Peralta et al. (2015) used molecular information to ask how phylogenetic determinants of food web structure changed across habitat edges, showing that changes in land use affected patterns of phylogenetic congruence among interacting trophic levels. Thus, what we do to our habitats may select for different levels of coevolved interactions.

Overall, terrestrial studies applying DNA barcodes to simultaneously resolving the nodes and the links of full food webs (or substantial parts of them) are still few - but we expect the next few years to bring a substantial growth in this literature. For one such example, we refer the reader to the case study summarized in Box 1.

\section{Box 1. Barcoding an Arctic food web}

To illustrate a systematic attempt at using DNA barcodes to reconstruct all aspects of food web structure, we use a long-term study aimed at documenting the food web of the Zackenberg valley in High Arctic Greenland. Chosen for its low species richness, this area offers a simplified food web where sampling effects can be minimized, while the coverage of the local species complement can be maximized.

Targeting this system, we have used a range of sampling techniques to document the local terrestrial, macroscopic fauna and vascular flora as extensively as possible since 2009 (Várkonyi and Roslin 2013; Wirta et al. 2016). Our first key aim has been to generate a list of species present in the food web 
(Várkonyi and Roslin 2013; Wirta et al. 2016). By then generating a comprehensive library of speciesspecific DNA barcodes for the majority of animals and plants encountered in the area, we have established a tool for identifying essentially any biological sample from the region (Wirta et al. 2016). For macroscopic animals, we have used CO1 barcodes (Hebert et al. 2003); for plants we have used rbcLa and ITS2 (Chen et al. 2010; Hollingsworth 2011; Hollingsworth et al. 2011; Kuzmina et al. 2012). Drawing on the molecular identification tools thus generated, we have verified the identity of each node in the food web (Wirta et al. 2016), and reconstructed the trophic links among three key taxa in the local ecosystem: birds, spiders and insects (Wirta et al. 2014, 2015a, 2015b).

For this species complement, cryptic taxa are few, and most species distinguishable by morphological means (Wirta et al. 2016). Among the local animal taxa, DNA barcodes (CO1) offered high resolution in discriminating species, with $92 \%$ of morphologically distinguishable taxa assigned to unique Barcode Index Numbers (BINs; Ratnasingham and Hebert 2013) and 93\% to monophyletic clusters. For vascular plants, resolution was lower, with $54 \%$ of species forming monophyletic clusters based on barcode regions rbcLa and ITS2. This lack of resolution at the level of plant species is partly reflective of arctic genera encompassing relatively young and/or little-diverged taxa (Kuzmina et al. 2012; Saarela et al. 2013). At the level of genera, resolution proves better, with $78 \%$ of the genera assessed forming monophyletic clades for the two gene regions combined. Thus overall, the resultant tools offer good discrimination in resolving the feeding links among dominant taxa (Fig. 3), with most animal samples attributable to species and most plants to at least genera.

Applying molecular analyses to host-parasitoid associations (Wirta et al. 2014; Fig. 3), as well as the prey choice of spiders (Wirta et al. 2015a) and birds (Wirta et al. 2015b), we have resolved a food web much more complex than previously thought (Fig. 3). Far from the simplistic structure originally envisaged by Summerhayes and Elton (1923; as previously challenged by Hodgkinson and Coulson 2004), it depicts arctic food webs as complex constructs, densely linked by live interactions (Wirta et al. 2015b). This reinterpretation of the structure comes with important implications for how we might expect the system to react to current Arctic warming: rather than a series of disconnected food chains, where each species is primarily dependent on abiotic conditions, we should expect an organically linked system, where a change in one taxon may reverberate widely across the network of biotic interactions (Wirta et al. 2016). 
That the application of DNA barcodes as a tool has a major impact on how we perceive of the system is shown by a simple contrast offered by Wirta et al. (2014; cf. Fig B1): compared with variation among networks quantified at sites from Hawaii to the UK, the properties of our web varied as much or much more depending on the techniques used to dissect it. When reconstructed by traditional rearing alone, each host species in the Zackenberg food web appeared to be attacked by the lowest number of parasitoid taxa (i.e., to show the lowest generality) among the webs compared - but when molecular information was added, the number raised to the highest. In terms of the number of predator taxa per prey species (vulnerability), absolute variation between local webs reconstructed by different techniques proved almost five times as large among techniques as variation among webs from different parts of the world. This finding brings a striking message to comparisons across latitudes: DNA barcodes actually offer so high resolution that taken at their face value, straight contrasts with webs reconstructed by other techniques will be simply misleading. How the Arctic web now resolved compares to food webs from other latitudes is thus too early to say - as fair comparisons across latitudes will have to await more data points of similar resolution.

As the next few steps in resolving the high Arctic food web of Zackenberg, we are currently expanding the core food web generated to date to the full network of ecological networks (compare Fig. 2E). Ongoing initiatives at Zackenberg apply molecular tools to incorporate plant-pollinator interactions (cf. Bell et al. 2016; this issue) and plant-fungus interactions (cf. Toju et al. 2014), in each case building on next generation, high-throughput techniques. To extend our capacity of species-level recognition, to derive augmented information for community phylogenomics, and to improve our capacity of sample quantification (cf. Fig. 5D), we are supplementing our reference library as so far based on single loci towards larger parts of the genome. These improved techniques are already being applied to the comprehensive identification of two decades of bulk samples generated by the biomonitoring programme (Schmidt et al. 2012) of Zackenberg.

Overall, what the molecular techniques have contributed to our dissection of the Zackenberg food web is the capacity of identifying all samples from the food web - regardless of what biotic interaction they have been involved in - thereby offering high resolution in reconstructing the current structure of the food web, and in detecting recent changes coinciding with a rapid change in the Arctic climate. 


\section{Aquatic studies}

\subsection{Clarifying the nodes of aquatic food webs}

In recent years, DNA barcodes have proven a valuable asset in identifying the nodes of aquatic-dwelling food webs, i.e. marine and fresh water organisms, from microbes through plankton to higher trophic levels. Approaches today span initiatives aimed squarely at assembling reference libraries of barcode sequences for known species, attempts to clarify ambiguities in traditional taxonomy, efforts to reliably assign unknown specimens to known species, and the flagging of potential cryptic species (with examples from marine ecosystems reviewed in Bucklin et al. 2011; Radulovici et al. 2010; Trivedi et al. 2015, and examples of fresh water fish in April et al. 2011). Many aquatic taxa represent a fruitful target for DNA barcoding due to their high diversity (of the 35 animal phyla that have been described so far, 14 phyla are marine endemics), and their high number of rare species. From a systematic perspective, many groups are poorly known - and most groups are both small and lack any reliable morphological characters for easy identification (e.g. Radulovici et al. 2010; Leray and Knowlton 2015). Hence, to delimit the nodes and to compare the role of the same node (population) among aquatic food webs of the world, it is evident that DNA barcoding does offer a much-needed tool, and a vital complement to traditional morphology-based identification. At the same time, the lack of consistent morphological character poses a particular problem for numerous taxa with diverse developmental stages. This creates the specific challenge of linking the early developmental stages with the adult forms (e.g. of eggs to meroplanktonic larvae and benthic adults; e.g. Barber et al. 2006; Webb et al. 2006; Pegg et al. 2006; Victor et al. 2009; Lindequet et al. 2013), or merely combining different growth forms within groups characterized by large phenotypic plasticity (reviewed in, e.g., Padilla and Savedo 2013). Indeed, cryptic species have been shown to be widely distributed in marine (Knowlton 1993) as well as in fresh water systems (Balian et al. 2010). While different life stages of the same species may occupy different positions within the web, they together account for the demography of the species' population. Likewise, generalists turning out to be specialized cryptic species, each with their more restricted diet specificity, change the link structure of the web (Figs. 1; 2A). Both considerations render the resolution of adequate taxonomy a key part of understanding food web dynamics. 
While the number of aquatic $\mathrm{CO} 1$ barcodes is increasing, several other markers are also widely used. These markers include the mitochondrial cytochrome b gene (cyt b), 18S rDNA, the internal transcribed spacer region (ITS), or rbcL, with their relative utility depending on the node targeted within the food web (e.g. Bucklin et al. 2011; Radulovici et al. 2010; Trivedi et al. 2015 and references therein). In marine systems, mitochondrial CO1 and 16S rDNA sequences are still the most widely-used markers. However, the simultaneous use of several markers has been proven to increase the accuracy of the identification of the nodes (e.g. Deagle et al. 2009). In a study applying both $16 \mathrm{~S}$ and CO1, high variability was found among the markers in terms of their coverage of prey groups. More unique prey was identified with the $16 \mathrm{~S}$ compared to the $\mathrm{CO} 1$ barcoding markers (51 and 39 taxa respectively) with only 12 taxa identified by both genes (Bowser et al. 2013).

Regardless of what marker is adopted, the main factor limiting accurate taxonomic assignments using DNA sequences is so far the incompleteness of reference databases (e.g. Bartley et al. 2015). Where land diversity patterns and their predictors are known for numerous taxa (Gaston 2000), aquatic barcoding lags far behind the terrestrial counterpart (Radulovici et al. 2010): only a fraction of aquatic diversity has been barcoded (9.5 $\%$ of all known species, and listed by phylum in Bucklin et al. 2011). As an example hereof, fish are among the most intensively studied and barcoded marine groups, but the range of fish species currently barcoded within the global campaign FISH-BOL ranges from 25 and 72\% depending on the class (with an average of 34\%; Anonymous 2015a). The gaps in knowledge are particularly disconcerting when it comes to the diversity of smaller and fragile organisms, such as benthic and pelagic invertebrates, and phytoplankton (reviewed in Radulovici et al. 2010 and Trivedi et al. 2015) as well as deep sea regions. As an example, Leray and Knowlton (2015) recently reported a surprising amount of diversity in an intensive survey of the marine diversity of a small area from oyster reefs, across a range of geographic scales comprising a temperate location (Virginia, USA) and a subtropical location (Florida, USA). At the same time, however, only $10.9 \%$ of the sequences could be matched to reference barcodes in public databases. Valdez-Moreno et al. (2012) were able to match $94 \%$ of prey fish sequences to reference sequences in BOLD with a similarity exceeding $99 \%$, corresponding to reliable species-level identification. The remaining $6 \%$ could be identified 
to genus level. Of the distinct crustacean prey sequences (45) only 20 taxa could be identified from the BOLD and GenBank databases. The matches were primarily to order level, but only a single taxon could be identified to the species level. As pointed out by Leray and Knowlton (2015), these results highlight the enormous numbers of marine animal species that remain genetically unanchored to conventional taxonomy.

\subsection{Clarifying the links of aquatic food webs}

Quite encouragingly, some model systems and aquatic taxa are already reaching a level where extant reference libraries allow the adequate identification of a large fraction of trophic links (for an example, see Box 2). Fish offers the most promising illustration of the functional utility achieved from an extensive reference library (Valdez-Moreno et al. 2012; cf. above). Another example derives from a study of the gut contents of North-American catfishes: here, Moran et al. (2015) were able to match $86 \%$ of lightly or moderately digested stomach contents and $66 \%$ of heavily digested prey fish sequences to reference sequences in GenBank. With global databases being increasingly populated, more and more taxa will reach similar levels - but this can only be achieved by joint efforts, aided by standardization of marker choices among research groups. (At the same time, we should emphasize that much can be achieved with Molecular Operational Taxonomic Units or MOTUs, since MOTUs form just as valid nodes within food webs as do Linnean taxa; see below under Emerging opportunities for improving food webs).

Reflecting the increasing availability of reference libraries, descriptions of smaller trophic modules are emerging from more and more aquatic food webs, as building on species identification (prey) in the stomachs, pellets, or feces of predators. In aquatic food webs, DNA-based approaches have already been applied to a wide range of taxa, including both specimens collected in the wild and data collected in feeding trials. In most cases, these studies build on one of two techniques: specific PCR primers designed to reveal predation on one or a few specific prey taxa, or the amplification of DNA using universal or group-specific primers as followed by sequencing of the amplicon. Diet studies of these types have been applied extensively to marine taxa ranging from higher trophic levels (e.g. Deagle et al. 2005; Dunn et al. 2010; Meheus et al. 2014) through marine birds (e.g. Deagle et al. 2007; Bowser et al. 2013) and fish (e.g. Moran et al. 2015) to 
different invertebrates and lower trophic levels (e.g. Jarman et al. 2002; Nejstgaard et al. 2003; Blankenship and Yayanos 2005; Leal et al. 2014b; Olsen et al. 2014; Hu et al. 2015; reviewed in Calado and Leal 2015). DNA-based approaches have also yielded breakthrough dietary analyses in complex freshwater systems (e.g. Corse et al. 2010; Carreon-Martinez et al. 2011; Bartley et al. 2015). Most of the studies to date attest to the effectiveness of DNA-based analysis, especially when combined with morphological analysis (e.g. Casper et al. 2007; Braley et al. 2010; Alonso et al. 2014), and offer new insights in trophic ecology.

Compared to studies relying on more direct observations, DNA markers offer a clear-cut advantage: the potential for studying feeding relations among species and life stages as being too small (such as the nauplii of copepods; Graig et al. 2014, and bivalves; Maloy et al. 2013) or as inhabiting environments too inaccessible (such as the deep-sea; Olsen et al. 2014) for their feeding habits to be directly observed. As an example, Maloy et al. (2013) successfully combined general eukaryotic primers with a predator-specific endonuclease restriction enzyme and a blocking primer to explore the feeding ecology of bivalve larvae, which resulted higher taxonomic resolution of the prey items than with more traditional approaches. Such approaches to studying the trophic interactions of small, larval stages of planktonic consumers offer an unparalleled contribution to understanding the food webs of the sea, as approximately $70 \%$ of all marine invertebrates are characterized by planktotrophic larvae - most of which are relatively small $(<1 \mathrm{~mm}$; Thorson 1950). The study of Olsen et al. (2014), on the other hand, offered new insights into the trophic interactions of the amphipod Themisto abyssorum in an inaccessible environment: the deep sea and hydrothermal vent and cold-seeps. Based on the resultant data, T. abyssorum was simultaneously assigned to more than one trophic level, suggesting that it should be regarded as an omnivore and not a strict carnivore as had previously been suggested. Similarly, among often brittle and transparent gelatinous taxa, DNA barcodes increase the detectability of prey items previously difficult to score (Méheust et al. 2014; Hauff et al. 2015).

An increasing number of studies using next-generation sequencing (including DNA metabarcoding) has offered particular insights into the broad range of taxa consumed by aquatic organisms (e.g Deagle et al. 2009; Deagle et al.2010; Murray et al. 2011; O’Rorke et al. 2012b, 2014; Leray et al. 2013, 2015; Box 2). 
However, their main focus has been on the dietary analysis of larger taxa such as seals, penguins and fish and in marine over freshwater systems. As an example from smaller-bodied taxa, O’Rorke et al. (2012b) used a high-throughput amplicon sequencing approach, two short regions of the 18S rRNA gene, to determining the diet of larvae of Western Rock Lobster (Panulirus cygnus). Here, larval gut contents were assigned to challenging prey taxa, such as transparent gelatinous zooplankton, with a resolution unparalleled by other methods. Thus, it is evident that the DNA metabarcoding approach has the potential of simultaneously resolving the nodes and the links of aquatic food webs, and can further our understanding of how these webs are structured.

\subsection{Resolving substructuring within aquatic species and populations}

A few studies to date have sampled specific aquatic predator taxa more deeply, and demonstrated the occurrence of trophic segregation between different life stages (e.g. age, breeding status and sex; Alonso et al. 2014; Jo et al. 2014). Thus, they suggest that different population segments chose different diets. In a groundbreaking study, Jo et al. (2014) were able to include smaller-sized predators (i.e., juveniles) into a high-resolution (i.e., species-level) exploration of the diet used by a freshwater, carnivorous fish, the largemouth bass (Micropterus salmoides). Here, the results indicated the presence of ontogenetic diet shifts. Alonso et al. (2014) combined DNA sequencing (16S rRNA mitochondrial gene) with conventional, morphological analysis to investigate the diet of Cory's shearwater (Calonectris diomedea). The molecular approach increased taxonomic resolution by revealing 17 additional prey taxa, and provided direct evidence of trophic segregation according to breeding status, sex, breeding phase (pre-laying versus chick rearing) and year within the same population. Such changes in diet have rarely been shown in seabirds. Overall, these patterns detected within species add to the detail of food web structure, and highlight the need for understanding shifts in trophic links involving different members of one and the same population.

\subsection{Reconstructing larger modules within aquatic webs}


To date, studies applying DNA barcodes to simultaneously resolving the nodes and the links between several trophic levels in aquatic food webs are nearly absent. A study by Browser et al. (2013) employed metabarcoding to investigate puffin (predator) - herring (prey and predator) - prey relationships using a multi-locus (16S and CO1) approach and next-generation sequencing. Here, the inclusion of herring diet proved critical to understanding puffin diet, as it allowed the researchers to tease out the effects of secondary consumption (i.e. prey being consumed by the herring before being consumed by the puffin). This is important, as until today, the extent of errors in food web analysis caused by secondary prey co-amplification has not been quantified in aquatic systems (Leray et al. 2015, see Sheppard et al. 2005 for an example in a terrestrial system). The study also demonstrated the general utility of metabarcoding targeting multiple markers $(\mathrm{CO} 1,16 \mathrm{~S})$ in aquatic food web construction, as it revealed stark differences in the type, number, and coverage of taxa detected by each marker. Overall, only $20 \%$ of all prey taxa were detected by both markers. Thus, in aquatic ecosystems, marker choice has a considerable impact on the resultant dietary data (see more in Deagle et al. 2014), and on the interpretation of how nodes link to the surrounding food web.

What is evident is that the number of studies using DNA barcodes in constructing nodes and links in aquatic food webs is currently increasing, and that the development of methods is picking up speed (for example for recent papers of methods involving blocking primers, see O'Rorke et al. 2012a; Leray et al. 2013; for improved quantifications, see Thomas et al. 2014). Thus, we expect the next few years to bring studies where DNA barcodes have been applied simultaneously to resolve the nodes and the links of "full" aquatic food webs (or substantial parts of them). To illustrate the scope for aquatic studies applying molecular approaches similar to those recently utilized in terrestrial systems (Box 1), we point to an ambitious study targeting a tropical reef ecosystem in French Polynesia (Box 2).

\section{Box 2. Barcoding a coral reef food web}

To illustrate a systematic attempt to using DNA barcodes in reconstructing food web structure in a marine environment, we turn to a project aimed at documenting the food web of a tropical ecosystem of French Polynesia - the Moorea Biocode-project. Chosen for its high biodiversity, this model system offers an 
ambitious example of how molecular techniques can contribute to the dissection of a complex coral reef food web by allowing the identification of all nodes in the web.

Paralleling the terrestrial initiative described in Box 1, the Moorea BIOCODE project represents an "All Taxa Biotic Inventory”. Thus, it aims to provide a reference library of genetic markers for all non-microbial species of a complex tropical ecosystem (Anonymous 2015b). Such a resource will allow researchers to overcome many challenges in morphology-based identification when species-level information is required. As a result, it will contribute to novel understanding of community-level processes and biotic interactions in a marine setting.

Targeting the reef system, the Moorea BIOCODE project used a broad range of sampling techniques to document the diversity of the local reef ecosystem as extensively as possible between 2006 and 2010; Anonymous 2015b). All specimens were identified morphologically to the lowest taxonomic level possible, photographed and their tissue sampled for DNA barcoding. The project successfully assigned a species-specific barcode - in most cases the cytochrome c oxidase subunit I (COI) - to $\sim 4000$ coral reef species ( $>2 \mathrm{~mm}$ ) in 28 phyla, with an emphasis on arthropods, chordates and molluscs (Leray et al. 2012).

As an example of the utility of the Moorea Biocode barcode reference library, it has been applied to fish which exhibit spectacular phenotypic changes during their ontogeny. This change in appearance with age causes great challenges in the identification of early stages. Using DNA barcodes from BOLD and Moorea Biocode, Hubert et al. (2014) were able to identify $75 \%$ of the fish larva to the species level, using a $98 \%$ similarity threshold. For $20 \%$ of the larvae analyzed, identification still proved problematic due to misidentifications in the DNA barcode reference libraries. Thus, this study stresses the crucial importance of extensive, well-curated reference libraries for studies aimed at identifying species as the nodes of food webs.

The molecular identification tools generated by the Moorea Biocode initiative have also been applied to document trophic links among coral reef fish and invertebrates. As an example hereof, DNA barcoding was combined with morphological gut content analysis to identify individual prey remains in the stomachs of five common predator fish (Leray et al. 2012). Overall, $94 \%$ of the prey remains were identified to the species level by matching CO1 sequences from prey with the BIOCODE reference library - as compared to a success rate of less than $2 \%$ when using morphological identification, and a $16 \%$ 
identification success when COI sequences were compared with reference sequences in GenBank. Overall, this study by Leray et al. (2012) then showed how prey identification using DNA barcoding can provide novel insights into resource partitioning, predator feeding behavior and the potential consequences of predation on ecosystem function.

A metabarcoding approach documented an even broader taxonomic distribution of species consumed among three fishes with contrasting feeding regimes (Leray et al. 2013). Here, a total of 344 OTUs spanning 14 different phyla were identified among the prey items. Among all prey OTUs, 52.5\% showed a direct match with a reference barcode, most of which derived from the Moorea BIOCODE sequence library. The lower proportion of species-level assignments compared to the previous study (cf. Leray et al. 2012) demonstrate the ability of metabarcoding to detect under-represented phyla and smallsized species $(<2 \mathrm{~mm}$ adult size). Similar high-throughput sequencing tools were used to demonstrate remarkable diet partitioning among coral-dwelling fish previously thought to feed on the same invertebrate prey. The study found that nearly $80 \%$ of prey items had been consumed by only one predator species (Leray et al. 2015).

Overall, the taxonomic resolution provided by the Moorea Biocode sequence library offers an unprecedented view of the highly complex interaction web of coral reefs. As examples of the next few steps building further from the Moorea Biocode project, McCliment et al. (2012) have initiated an inventory of microbial life present in this rich tropical environment. Likewise, the Moorea IDEA project started in 2013 aims to make Moorea the first ecosystem in the world to be replicated in a detailed digital form (Cressey 2015; Anonymous 2015c). This will hopefully allow the combination of insights compiled in the Moorea Biocode project — such as which species are present at certain ocean spots, or which species are eaten by each other - with data on weather, ocean currents and human population parameters to allow sustainable ecosystem management.

Taken together, the Moorea BIOCODE project highlights the potential of barcoding initiatives in a marine environment, and the use of DNA metabarcoding as an approach to provide taxonomic resolution in predator-prey interactions and in food web reconstructions.

\section{Perspectives}


What our review of the field has brought forth are similar opportunities and challenges in applying DNA barcodes to constructing food webs in both terrestrial and aquatic systems. In each environment, molecular approaches to reconstructing the nodes and the links of webs (Figs 1,2) are adding new detail and exposing unexpected complexity. Overall, these tools are transforming our view on how nature is structured: food webs are simply proving to be composed of more nodes linked in more ways than we ever knew (for examples, see Boxes 1 and 2). As the main challenge, studies in both environments are struggling with building comprehensive reference libraries - with the challenges faced in the aquatic environment currently superseding more rapid advances in the terrestrial environment.

\subsection{Emerging differences, similarities and links between the terrestrial and aquatic realms}

With rapid methodological advances within the terrestrial and aquatic realms, a key question is whether we will ultimately find food webs of similar or dissimilar structure in the respective environments. In terms of aquatic webs, initial work concluded that marine food webs are fundamentally different from other kinds of food webs (Cohen 1994, Link 2002). Yet, these initial patterns appear partly determined by resolution: later work based on more highly and evenly resolved webs suggest that descriptors of marine webs will indeed fall within the ranges observed in other webs (Dunne et al. 2004). In terms of structuring forces, the current consensus suggests that macroscopic aquatic food webs are structured by body size rather than by anything else (McCann 2014): aquatic organisms tend to eat across a range of size - and also tend to shift to larger prey items when growing themselves. As such, many aquatic webs seem characterized by extremely generalized feeding strategies, and by an inherently flexible architecture. This view is indeed supported by the wide diets described by recent molecular studies (cf. our review above). Among terrestrial webs, some recent research focuses on size as a structuring factor, with soil food webs being among the environments where trophic interactions may be strongly structured by size (Digel et al. 2014; Lang et al. 2014). In other environments, the structuring force seems to vary with the specific type of interaction examined (Petchey et al. 2008; Dunne et al. 2013). Indeed, multiple recent studies stress the need for identifying common rules dictating who interacts with whom within large communities (Gravel et al. 2013; Morales-Castilla et al. 
2015; Bartomeus et al. 2016). Interestingly, when food webs from different environments are collated in joint analyses of e.g. latitudinal trends, partly different patterns appear in different environments, again suggesting slightly different drivers in different systems (Schleuning et al. 2012; Morris et al. 2014; Cirtwill et al. 2015). The similarities and differences between terrestrial and aquatic food webs show the need for cross-fertilization. What explicitly emphasizes the need for joint methodological development is the extent to which specific methodology has been shown to affect our perception of even single food webs (see Box 1): how we seek comes with a major impact on what we find. Broader comparisons across the terrestrial and aquatic realm must thus rely on a quest for equally sensitive, molecularly-based approaches, or we risk finding differences attributable to differences in methodology alone (cf. above for marine webs).

Another question that DNA-based techniques will help us resolve is the extent to which energy, nutrients and species actually move between terrestrial and aquatic environments and link food webs across systems. Of key interest is the extent to which local productivity at different trophic layers, population dynamics and community structure is affected not only by local processes and energy accumulation but also by the inflow of energy and biomass from the other realm (Polis et al. 1997; Sabo and Power 2002a; Hoekman et al. 2011; Dreyer et al. 2012; Hocking and Reynolds 2011). Nutrient-rich wetlands, lakes and marine areas often provide productive habitats not only for aquatic but also for terrestrial species consuming taxa emerging from the water (Sabo and Power 2002b; Paetzold et al. 2008; Mellbrand and Hambäck 2010). Not surprisingly, densities of terrestrial predators are typically higher close to various water bodies and depend on the amount of inflow of prey on the shore-line (Paetzold et al. 2011; Dreyer et al. 2012). DNA barcodes (and other molecular tools; e.g., Collier et al. 2002; Kolb et al. 2010; Mellbrand et al. 2010) allow us to trace these flows with new accuracy, and to thus understand the real links between terrestrial and aquatic food webs.

\subsection{Emerging opportunities for improving food webs}

\subsubsection{ADDED RESOLUTION AND REPEATABILITY}


At present, the main deliverable of DNA barcodes to food web studies is added resolution and added access to species groups and types of interactions earlier evading direct study. Across aquatic and terrestrial systems, DNA barcodes allow the identification of 'true' species rather than diffuse compound taxa, and the detection of feeding links among even secretive taxa turning their food into nondescript soups (thus leaving no morphologically-recognizable characters for other means of diet analysis). Thus, if communities are defined as sets of interacting populations, then molecularly-resolved food webs allow us to build our networks from the units that they are supposed to depict. By using molecular markers which are much more tightly linked to the evolutionary history of the organism than morphological characters, we get a more accurate picture of the node boundaries in our network regardless of whether or not we have a name for that node. In many cases, we will still lack a traditional scientific name for a node detected, as formally-identified voucher specimens are yet to be included in reference libraries (and more often than not, yet to be described to science; Leray and Knowlton 2015). To face such challenges, DNA barcodes do offer a provisional solution. For less well-studied taxa, they allow the definition of interim taxonomic units (sensu BINs; Ratnasingham and Hebert 2013), to which trophic information can be collated (e.g. Wirta et al. 2014, 2015a, 2015b). Thus, even among the multitude of still-to-be described species, they allow us to compare the role of taxa in food webs of different regions and ecosystems, without the need to await reference libraries to be fully populated, or new species to be formally described.

Nonetheless, we should also celebrate the hurdles already passed. For major faunas like the beetles of Europe (Hendrich et al. 2015) or Finland (Pentinsaari et al. 2014), DNA barcodes of substantial parts of known taxa are already included in the public data base of BOLD (Ratnasingham and Hebert 2007). For charismatic taxa like Lepidoptera: Sphingidae and Lepidoptera: Saturniidae, DNA barcodes are now available for about $90 \%$ of world species (encompassing about 5000 species or subspecies; R. Rougerie, personal communication, 2015). Of 16,200 North-American Lepidoptera, CO1 barcodes are available for about $63 \%$ of species (Anonymous 2015d). For smaller areas, DNA barcodes are available for practically every lepidopteran (and trichopteran) species (M. Mutanen, personal communication, 2015). For Artic and alpine plants, not only are single or dual-locus DNA barcodes available for the entre regional flora of Svalbard (Inger Greve Alsos, personal communication, 2015), but projects now under way to reconstruct the whole chloroplast genome 
and nuclear ribosomal sequences of all vascular plant species occurring in the Alps (see Anonymous 2015e) and in Norway (Inger Greve Alsos, personal communication, 2015). The latter type of resources will greatly facilitate approaches such as depicted in Fig. 5D; see also Bell et al. 2016). Thus, we are already out of good excuses for not tackling major patterns in plant-herbivore (Lewinsohn and Roslin 2008; Forister et al. 2015; cf. García-Robledo et al. 2013a, 2013b) or host-parasitoid (Morris et al. 2014; cf. Wirta et al. 2014) associations with the added resolution offered by molecular means.

By anchoring the nodes of our food webs in molecular information, we are also achieving another advantage - this will, to a certain extent, allow us to both proof and future-proof our results. In terms of alreadyconstructed food webs, DNA barcoding allows a way of validating previous topology: by resolving the same web by a new technique, ecologists will be able test whether their food webs are accurately described and well-sampled. In terms of future analyses of our material, the use of molecular characters allow future ecologists to return to our data and improve them with novel information. For morphological data sets, revaluating webs in light of taxonomic revisions is usually impossible, as authors rarely deposit all the samples they collect in national collections. For published DNA information, future analysts can retroactively apply identifications to currently unknown taxa and assess their validity within the broader range of molecular variation that exists outside the original sampled population. This will also allow later studies to adjust food web topology in the light of later-accumulated data. In other words, by using an identification technique less prone to opinion and personal bias, and by generating digital data, we increase the value of our studies in the long term.

\subsubsection{QUANTIFYING INTERACTIONS}

In terms of quantifying interaction frequencies, the exact contribution from DNA barcodes is so far hotly debated. While in studies based on next-generation, parallel sequencing, the number of reads attributable to each prey has sometimes been used as a proxy of prey abundance in the diet (Fig. 5A); other studies have emphasized how inference regarding actual prey intake is still complicated by first digestion within the consumer (e.g., Harwood and Obrycki 2005; Greenstone et al. 2014), then by sample extraction and 
amplification. Any taxon-specific bias introduced during each of these phases will lead to compounded error propagation in downstream analyses (Pompanon et al. 2012; Deagle et al. 2013; Piñol et al. 2014; Clare 2014). While the jury is still out with respect to the quantitative information content of PCR products, three alternative approaches have been proposed to circumvent these biases (Fig. 5B-D). Of these, the most widely applied approach is to resort to estimating probability of occurrence from presence-absence in samples: in a sample of many droppings (or many gut contents, each treated as a replicate unit), the incidence of a given prey taxon can be assumed to reflect rough consumption rates (e.g., Clare et al. 2014b, 2014c). As an alternative, studies using quantitative PCR have been proposed to quantify the abundance of DNA present in the extract (e.g., Bowles et al. 2011). In aquatic systems, this has been a particularly active line of research recently, with examples including both samples from wildlife (e.g., Nejstgaard et al. 2008; Murray et al. 2011; Durbin et al. 2011; Leal et al. 2014a; O'Rorke et al. 2015) and from data collected in controlled feeding trials, as aiming to calibrate DNA-based diet quantification (e.g., Deagle et al. 2010; Bowles et al. 2011; Murray et al. 2011; Thomas et al. 2014). Here, the results are so far mixed. Finally, recent PCR-free approaches propose to circumvent any amplification biases and offer straightforward quantifications of DNA amounts in the guts of predators (Paula et al. 2015). To be efficient, the latter method will likely depend on matching reads with target regions larger than the traditional barcoding region (Paula et al. 2015; Tang et al 2015).

Of the approaches outlined above (Fig. 5), only the incidence-based approach has been successfully applied to resolve structures at the level of full food web modules (Wirta et al. 2015a,2015b), but much potential promise resides in PCR-free methods (Paula et al. 2015). In developing them, we should remember that knowing more about the diet of individual predators does not compensate for knowing something about more predator individuals. Within food webs, link strength is set by the number of individuals interacting with each other (Fig. 1), and thus adequate sample size at the level of individuals is a key concern. Yet, with the current increase in sequencing and computing power, we believe that we will achieve improved resolution both within and between individuals. Clearly, inference regarding actual prey intake is still complicated by decay rates during digestion (Harwood and Obrycki 2005; Greenstone et al. 2014; Paula et al. 2015), but there is no reason why this could not be explicitly accounted for by modelling. 


\subsection{Towards networks of ecological networks in space and time}

Where quantifying interaction strength with higher precision is essentially doing what we have already done (albeit with new precision and in new systems), we should not content ourselves with applying DNA barcodes to doing just more of the same that we were already doing with morphological tools. Ultimately, what DNA barcodes - and more generally DNA-based tools - offer to food web research is the potential for expanding beyond past descriptions of specific types of interactions within larger webs to full webs. While most of the earlier studies have been confined to small modules targeting specific guilds (Van Veen et al 2006, Pocock et al 2012; Sauve et al. 2015), what we should aim for are comprehensive approaches to how different types of interactions tie into each other (cf. Pocock et al. 2012; Wirta et al. 2015). Where the first such "network of ecological networks" have been forced to use different methods to quantifying different interactions (Pocock et al. 2012; Sauve et al. 2015), DNA barcodes do offer universal tools adaptable to "all" types of interactions (e.g., Clare et al. 2014a; Bell et al. 2016; Evans et al. 2016).

Building larger networks will allow food web ecologists to test one of their key beliefs: that sub-webs capture key elements of the larger webs of which they are part, and that the features and dynamics of smaller webs will scale up to larger webs. Several recent studies have pointed to fundamentally new insights to emerge from the fusion of several types of interactions into larger networks (Ings et al. 2009; Fontaine et al. 2011; Kefi et al. 2012; Evans et al. 2013; Lurgi et al. 2015). Importantly, if different submodules formed by different guilds and interaction types within webs (cf. Fig. 2E) prove only weakly linked (as suggested to be the case for the web examined by Pocock et al. 2012), then we may perform rather well while studying them individually. However, this we cannot know before many more and larger webs have been dissected.

Moreover, individual guilds can also be cross-linked via indirect interactions, e.g. by interspecific competition - and of this, the static structure revealed by a snapshot will reveal only little. Indeed, it is in the reconstruction of the entire interaction web and in combining a snapshot of structure with some measure of dynamics that system-level understanding resides. Four vistas emerge as particularly appealing to us, each 
drawing on molecular tools beyond "traditional" DNA barcodes, yet building directly on the fundament laid by previous DNA barcode research:

First, new techniques offer new clues to interactions, as reviewed by Clare et al. 2014. For reconstructing interactions, we may turn to DNA traces left behind in the saliva of a chewed fruit, the gut epithelial cells on deposited seeds (González-Varo et al. 2014; Bell et al. 2016), prey DNA contained in predator scats, or pollen carried by a bee, moth or bat (Clare et al. 2013; Clare 2014). Thus, we are, in effect, tapping into fundamentally new sources of information on who interacts with whom. The key word for these approaches is the non-invasiveness of approaches (where needed). The use of DNA allows us to use tiny amounts of DNA in taxa as small as spiders (Sint et al. 2015) or copepod nauplii (Craig et al. 2014) or endangered land snails (Boyer et al. 2013). Adding to this is the fact that we may actually trace prey use to not only the predator species but the predator individual, by simply combining markers with adequate variation at the respective levels (for an example, see Vesterinen et al. 2016). This offers the basis of a new type of interaction ecology, resolving emergent patterns to contributions from multiple hierarchical levels - a theme currently developing faster for mutualistic than trophic interactions (see e.g., Valverde 2015). In interpreting this new information, food web ecologists will no doubt need to pay special attention to a wide range of potentially confounding factors. As we will mostly be dealing with clues from minute amounts of DNA, we will always need to ponder alternative sources for the DNA detected. There is always the very real risks of contamination, and in interpreting who has fed on whom, we also need to account for the potential for secondary predation - i.e. a predator feeding a prey who has fed on another prey (e.g., Sheppard 2005) etc. For a more in-depth discussion of technical complications, we refer the reader to recent reviews (King et al. 2008; Pompanon et al. 2012; Clare 2014) - but stress that in ecological forensics of food web research, we need to be every bit as rigorous in evaluating our evidence as in other types of forensics.

Second, new techniques offer the opportunity to finally break the limitations and biases imposed by restrictions on sample size. To achieve the massive sample sizes needed to capture realized interaction structure (cf. Fig. 2C), we may turn to the strategic, hierarchical tagging of compound samples. This will allow the efficient reconstruction of interaction structures across large ecological communities with several 
trophic levels (Evans et al. 2016). With sequencing power currently increasing as fast or faster than computing power (Carlson 2011), the challenge is not in how much interaction data we can generate, but how we can keep track of samples of 'who interacted with whom where' and process this information.

Third, the high spatiotemporal resolution offered by DNA-based techniques will allow us to move from the implicit assumption that species sometimes seen (or believed) to interact somewhere (Fig. 2B) will do so wherever and whenever they meet. While studies of ecological networks to date have mostly been concerned with the distribution of interactions within locations, and less so with the variation among locations, there is now ample evidence that ecological interactions vary in space and time (Poisot et al. 2012; Trojelsgaard et al. 2015). It is in resolving how interaction structure varies with the environment (see Poisot et al. 2012, 2015) that DNA barcodes will reveal their true potential. For generating the data needed to test and parameterize this new type of 'species interaction modelling', we see DNA-based techniques as a prime tool.

Fourth, molecular information will prove invaluable for combining information on interaction structure in ecological and evolutionary time. Where previous approaches have inferred a phylogenetic signal in interaction structure by combining interaction webs with phylogeny inferred from external sources, molecular information will allow the reconstruction of phylogenies from the samples themselves (Elias et al. 2013; Evans et al. 2016). Here, genomic approaches will add manifold to the information content as compared to classic DNA barcodes only (Papadopoulou et al. 2015; Andújar et al. 2015; Linars et al. 2015) again building a natural extension from previous studies advancing from one to multiple (Kress et al. 2005; Nyman et al. 2007, 2015; Kress et al. 2014) gene regions. Thus, it is evident how the use of single-locus DNA barcodes have laid a solid fundament for making full use of the information fountains now emerging.

We note that none of these vistas has any specific bias towards or anchoring in terrestrial or aquatic environments. They are opportunities allowing the unprecedented mapping of global biodiversity (Cristescu 2014; Ji et al. 2014; de Vargas et al. 2015), of the ways communities are structured, and of all types of ecological interaction networks. What we see is thus an immense chance for furthering research on ecological interactions in any environment. The theory behind aquatic and terrestrial food webs is universal, 
and so are the challenges facing empirical reconstructions of realized food web structures. In both systems, DNA-based techniques offer powerful tools for getting the nodes and the links just right. Overall, we believe that the joint adoption and further development of emerging molecular techniques offer an unparalleled opportunity for food web researchers working on different systems to join together towards general insights. In brief, what we envisage are bigger, better, phylogentically-structured networks across trophic levels and used for a range of interaction types.

Clearly, we should not lull ourselves into believing that applying new tools will automatically yield higherquality data or improved insights. The empirical reconstruction of any type of ecological network will still depend on having samples collected from the field - which could be done well or badly. We also reiterate the constraints and restrictions on current techniques, which we have consciously left for other, recent reviews (see references in introduction). Thus, it is the combination of good field sampling, in effective DNA approaches and in understanding the limits of them that the strong benefits for network research reside. Anyone working within this field is in for exciting times. In the words of Cohen et al. (1993, p. 253): “As more comprehensive, more detailed, more explicit webs become available, smaller, highly aggregated, incompletely described webs may progressively be dropped from analyses of web structure (though such webs may remain useful for other purposes, such as pedagogy). Consequently, any boundary between "good" webs and "bad" webs is neither sharp nor stationary." We believe that DNA barcodes will help us move this boundary.

\section{Acknowledgements}

We thank Bess Hardwick for invaluable help in preparing the figures, Matt Leray, Darren Evans and Michael Pocock for offering perceptive comments and illustrations, and the following sources for funding: the Academy of Finland (grants no. 276909 and 285803 to TR) and from the Ella and Georg Ehrnrooth Foundation (to TR). Two anonymous reviewers offered insightful comments which much improved the paper.

\section{References}


Ács, Z., Challis, R., Bihari, P., Blaxter, M., Hayward, A., Melika, G. et al. 2010. Phylogeny and DNA barcoding of inquiline oak gallwasps (Hymenoptera: Cynipidae) of the Western Palaearctic. Mol. Phylogenet. Evol., 55: 210-225.

Albrecht, J., Berens, D.G., Blüthgen, N., Jaroszewicz, B., Selva, N., and Farwig, N. 2013. Logging and forest edges reduce redundancy in plant-frugivore networks in an old-growth European forest. J. Ecol., 101: 990-999.

Allesina, S., and Pascual, M. 2009. Googling food webs: can an eigenvector measure species' importance for coextinctions? PLoS. Comp. Biol., 5: e1000494.

Alonso, H., Granadeiro, J.P., Waap, S., Xavier, J., Symondson, W.O., Ramos, J. A., and Catry, P. 2014. An holistic ecological analysis of the diet of Cory's shearwaters using prey morphological characters and DNA barcoding. Mol. Ecol., 23: 3719-3733.

Andújar, C., Arribas, P., Ruzicka, F., Crampton-Platt, A., Timmermans, M.J., and Vogler, A.P. 2015. Phylogenetic community ecology of soil biodiversity using mitochondrial metagenomics. Mol. Ecol., 24: 3603-3617.

Anonymous. 2015a. Fish barcode of life (FISH-BOL) [online]. Available from http://www.fishbol.org/ [accessed 27 December 2015].

Anonymous. 2015b. Moorea Biocode Project [online]. Available from http://mooreabiocode.org/ [accessed 27 December 2015].

Anonymous. 2015c. Island Digital Ecosystem Avatars (IDEA) Project [online]. Available from http://mooreaidea.org/ [accessed 27 December 2015].

Anonymous. 2015d. Barcode of Life Data Systems v4 beta [online]. Available from http://v4.boldsystems.org/ [accessed 27 December 2015].

Anonymous. 2015e. PHYLOALPS: Deciphering the evolutionary origins and maintenance of plant diversity in the Alpine Biodiversity Hotspot using next-generation sequencing and high performance computing [online]. Available from https://www.france-genomique.org/spip/spip.php?article112 [accessed 27 December 2015]. 
April, J., Mayden, R.L., Hanner, R.H., and Bernatchez, L. 2011. Genetic calibration of species diversity among North America's freshwater fishes. Proc. Natl. Acad. Sci. U.S.A., 108: 10602-10607.

Arai, M.N. 2005. Predation on pelagic coelenterates: a review. J. Mar. Biol. Assoc. U. K., 85: 523-536. doi:10.1017/S0025315405011458.

Baird, D., and Ulanowicz, R.E. 1989. The seasonal dynamics of the Chesapeake Bay ecosystem. Ecol. Monogr., 59: 329-364.

Balian, E., Harrison, I., Butchart, S., Chambers, P., Cordeiro, J., Cumberlidge, N., et al. 2010. Chapter 2. Diversity of species in freshwater systems: In Freshwater - the essence of Life. Edited by R.A. Mittermeier, T. Farrell, I.J. Harrison, A.J. Upgren, and T. Brooks., Conservation International and Cemex Conservation Book Series, Earth in Focus Editions, China. pp 50-89.

Banašek-Richter, C., Cattina, M.-F., and Bersier, L.-F. 2004. Sampling effects and the robustness of quantitative and qualitative food-web descriptors. J. Theor. Biol., 226: 23-32.

Barber, P., and Boyce, S.L. Estimating diversity of Indo-Pacific coral reef stomatopods through DNA barcoding of stomatopod larvae. Proc. R. Soc. Lond., B, Biol. Sci., 273: 2053-2061.

Bartley, T.J., Braid, H.E., McCann, K.S., Lester, N.P., Shuter, B.J., and Hanner, R.H. 2015. DNA barcoding increases resolution and changes structure in Canadian boreal shield lake food webs. DNA Barcodes, 3: 30-43.

Bartomeus, I., Gravel, D., Tylianakis, J.M., Aizen, M.A., Dickie, I.A, and Bernard-Verdier, M. 2016. A common framework for identifying linkage rules across different types of interactions. Functional Ecology, [in press], doi:10.1111/1365-2435.12666.

Belivanov, Y. K,. and Hambäck, P. A. 2015. The time scale of isotope signals in spiders: molting the remains of a previous diet. Entomol. Exp. Appl., 156: 271-278.

Bell, K., Brosi, B., De Vere, N., Keller, A., Richardson, R., Gous, A., and Burgess, K. 2016. Pollen DNA barcoding: current applications and future prospects. Genome, in press.

Berg, S., Pimenov, A., Palmer, C., Emmerson, M., and Jonsson, T. 2015. Ecological communities are vulnerable to realistic extinction sequences. Oikos, 124: 486-496.

Blankenship, L.E., and Yayanos, A.A. 2005. Universal primers and PCR of gut contents to study marine invertebrate diets. Mol. Ecol., 14: 891-899. 
Blüthgen, N., Menzel, F., and Blüthgen, N. 2006. Measuring specialization in species interaction networks. BMC Ecol., 6: 9. doi:10.1186/1472-6785-6-9.

Bowles, E., Schulte, P.M., Tollit, D.J., Deagle, B.E., Trites, A.W. 2011 Proportion of prey consumed can be determined from faecal DNA using real-time PCR. Mol. Ecol. Resour., 11: 530-540.

Bowser, A.K., Diamond, A.W., Addison, J.A. 2013. From puffins to plankton: a DNA-based analysis of a seabird food chain in the Northern Gulf of Maine. PLoS ONE, 8: e83152.

Boyer, S., Wratten, S.D., Holyoake, A., Abdelkrim, J., and Cruickshank, R.H. 2013. Using next-generation sequencing to analyse the diet of a highly endangered land snail (Powelliphanta augusta) feeding on endemic earthworms. PLoS ONE, 8: e75962.

Braley, M., Goldsworthy, S.D., Page, B., Steer, M., and Austin, J.J. 2010. Assessing morphological and DNA-based diet analysis techniques in a generalist predator, the arrow squid Nototodarus gouldi. Mol. Ecol. Resour., 10: 466-474.

Briand, F., and Cohen, J.E. 1984. Community food webs have scale-invariant structure. Nature, 307: 264266.

Brose, U., and Scheu, S. 2014. Into darkness: unravelling the structure of soil food webs. Oikos, 123: 11531156.

Brower, A.V. 2006. Problems with DNA barcodes for species delimitation:'ten species' of Astraptes fulgerator reassessed (Lepidoptera: Hesperiidae). Systematics and Biodiversity, 4: 127-132.

Brown, D.S., Ebenezer, K.L., and Symondson, W.O.C. 2014a. Molecular analysis of the diets of snakes: changes in prey exploitation during development of the rare smooth snake Coronella austriaca. Mol. Ecol. 23: 3734-3743.

Bucklin, A., Steinke, D., and Blanco-Bercial, L. 2011. DNA barcoding of marine metazoa. Ann. Rev. Mar. Sci., 3: 471-508.

Byrnes, J.E., Reynolds, P.L., and Stachowicz, J.J. 2007 Invasions and extinctions reshape coastal marine food webs. PLoS ONE, 2: e295. doi:10.1371/journal.pone.0000295.

Calado, R., and Leal, M.C. 2015. Trophic ecology of benthic marine invertebrates with bi-phasic life cycles: What are we still missing? Adv. Mar. Biol., 71: 1-70 
Carlson, R.H. 2011. Biology is technology: the promise, peril, and new business of engineering Life. Harvard University Press, Cambridge, MA.

Carnicer, J., Jordano, P., and Melian, C.J. 2009 The temporal dynamics of resource use by frugivorous birds: a network approach. Ecology, 90: 1958-1970.

Carreon-Martinez, L., and Heath, D.D. 2010. Revolution in food web analysis and trophic ecology: diet analysis by DNA and stable isotope analysis. Mol. Ecol., 19: 25-27.

Carreon-Martinez, L., Johnson, T.B., Ludsin, S.A., and Heath, D.D. 2011. Utilization of stomach content DNA to determine diet diversity in piscivorous fishes. J. Fish Biol., 78: 1170-1182.

Casper, R.M., Jarman, S.N., Gales, N.J., and Hindell, M.A. 2007. Combining DNA and morphological analyses of faecal samples improves insight into trophic interactions: a case study using a generalist predator. Mar. Biol., 152: 815-825.

Chen, S., Yao, H., Han, J., Liu, C., Song, J., Shi, L., et al. 2010. Validation of the ITS2 region as a novel DNA barcode for identifying medicinal plant species. PloS ONE, 5: e8613.

Christensen, V., and Pauly, D. (1992). ECOPATH II —a software for balancing steady-state ecosystem models and calculating network characteristics. Ecol. Model. 61: 169-185.

Cirtwill, A.R., Stouffer, D.B., and Romanuk, T.N. 2015. Latitudinal gradients in biotic niche breadth vary across ecosystem types. Proc. R. Soc. B. 282 doi:10.1098/rspb.2015.1589

Clare, E.L. 2014. Molecular detection of trophic interactions: emerging trends, distinct advantages, significant considerations and conservation applications. Evol. Appl. 1144-1157. doi:10.1111/eva.12225

Clare, E.L., Fraser, E.E. Braid, H.E. Fenton, M.B., and Hebert, P.D.N. 2009. Species on the menu of a generalist predator, the eastern red bat (Lasiurus borealis): using a molecular approach to detect arthropod prey. Mol. Ecol., 18: 2532-2542.

Clare, E.L., Schiestl, F.P. Leitch, A.R. and Chittka, L. 2013. The promise of genomics in the study of plantpollinator interactions. Genome Biol. 14: 207.

Clare, E.L., Goerlitz, H.R., Drapeau, V.A., Holderied, M.W., Adams, A. M., Nagel, J., et al. 2014a. Trophic niche flexibility in Glossophaga soricina: how a nectar seeker sneaks an insect snack. Funct. Ecol., 28: $632-641$ 
Clare, E.L., Symondson, W.O., Broders, H., Fabianek, F., Fraser, E.E., MacKenzie, A., et al. 2014b. The diet of Myotis lucifugus across Canada: assessing foraging quality and diet variability. Mol. Ecol., 23: $3618-3632$.

Clare, E.L., Symondson, W.O.C., and Fenton, M.B. 2014c. An inordinate fondness for beetles? Variation in seasonal dietary preferences of night-roosting big brown bats (Eptesicus fuscus). Mol. Ecol., 23: $3633-3647$.

Clare, E.L., Chain, F.J.J., Littlefair, J.E., and Cristescu, M.E. 2016. The effects of parameter choice on defining molecular operational taxonomic units and resulting ecological analyses of metabarcoding data. Genome, [in press] doi:10.1139/gen-2015-0184.

Cohen, J.E., Briand, F., and Newman, C.M. 1990. Community Food Webs: Data and Theory. Springer, Berlin, Germany.

Cohen, J.E. 1994. Marine and continental food webs: three paradoxes? Phil Trans R Soc Lond B 343: 57-69.

Cohen, J.E. (Ed.). 1989. Ecologists' Co-Operative Web Bank [ECOWeB]. Version 1.0. Machine-readable data base of foodwebs. Rockefeller University, New York, New York, USA.

Cohen, J.E., Beaver, R.A., Cousins, S.H., DeAngelis, D.L., Goldwasser, L. et al. 1993. Improving food webs. Ecology 74: 252-258.

Collier, K.J., Bury, S., and Gibbs, M. 2002. A stable isotope study of linkages between stream and terrestrial food webs through spider predation. Freshwater Biology 47: 1651-1659.

Corse, E., Costedoat, C., Chappaz, R., Pech, N., Martin, J.F., and Gilles, A. 2010. A PCR-based method for diet analysis in freshwater organisms using $18 \mathrm{~S}$ rDNA barcoding on faeces. Mol. Ecol. Resour., 10: $96-108$.

Craig, C., Kimmerer, W.J., and Cohen, C.S. 2014. A DNA-based method for investigating feeding by copepod nauplii. J. Plankton Res., 36: 271-2.75.

Cressey D (2015) Tropical paradise inspires virtual ecology lab. Nature 517, 255-256 doi:10.1038/517255a

Cristescu, M.E. 2014 From barcoding single individuals to metabarcoding biological communities: towards an integrative approach to the study of global biodiversity. Trends Ecol. Evol., 29: 566-571. 
Deagle, B.E., Tollit, D.J., Jarman, S.N., Hindell, M.A., Trites, A.W., and Gales, N.J. 2005. Molecular scatology as a tool to study diet: analysis of prey DNA in scats from captive Steller sea lions. Mol. Ecol., 14: 1831-1842.

Deagle, B.E., Gales, N.J., Evans, K., Jarman, S.N., Robinson, S., Trebilco, R., and Hindell, M.A. 2007. Studying seabird diet through genetic analysis of faeces: a case study on macaroni penguins (Eudyptes chrysolophus). PLoS ONE, 2: e831.

Deagle, B.E., Kirkwood, R., and Jarman, S.N. 2009. Analysis of Australian fur seal diet by pyrosequencing prey DNA in faeces. Mol. Ecol., 18: 2022-2038.

Deagle, B.E., Chiaradia, A., McInnes, J., and Jarman, S.N. 2010 Pyrosequencing faecal DNA to determine diet of little penguins: is what goes in what comes out? Conserv. Genet., 11: 2039-2048.

Deagle, B.E., A.C. Thomas, A.K. Shaffer, A.W. Trites, and Jarman, S. N. 2013. Quantifying sequence proportions in a DNA-based diet study using Ion Torrent amplicon sequencing: which counts count? Mol. Ecol. Resour., 13: 620-633.

Deagle, B.E., Jarman, S.N., Coissac, E., Pompanon, F., and Taberlet, P. 2014. DNA metabarcoding and the cytochrome c oxidase subunit I marker: not a perfect match. Biol. Lett., 10: 20140562.

Derocles, S.A.P., Evans, D.M., Nichols, P.C., Aifionn Evans, S., and Lunt, D.H. 2015 Determining plant leaf miner - parasitoid interactions: a DNA barcoding Approach. PloS ONE, 10: e0117872.

Derocles, S.A.P., Le Ralec, A., Besson, M.M., Maret, M., Walton, A., Evans, D.M., and Plantegenest, M. 2014 Molecular analysis reveals high compartmentalization in aphid-primary parasitoid networks and low parasitoid sharing between crop and noncrop habitats. Mol. Ecol., 23: 3900-3911.

Diehl, E., Mader, V.L., Wolters, V., and Birkhofer, K. 2013. Management intensity and vegetation complexity affect web-building spiders and their prey. Oecologia, 173: 579-589.

Digel, C., Curtsdotter, A., Riede, J., Klarner, B., and Brose, U. 2014. Unravelling the complex structure of forest soil food webs: higher omnivory and more trophic levels. Oikos, 123: 1157-1172.

Dreyer, J., Hoekman, D., and Gratton, C. 2012. Lake-derived midges increase abundance of shoreline terrestrial arthropods via multiple trophic pathways. Oikos 121: 252-258.

Dunn, M.R., Szabo, A., McVeagh, M.S., and Smith, P.J. 2010 The diet of deepwater sharks and the benefits of using DNA identification of prey. Deep Sea Res. Part I Oceanogr. Res. Pap. 57: 923-930. 
Dunne, J.A., Williams, R.J., and Martinez, N.D. 2002. Network structure and biodiversity loss in food webs: robustness increases with connectance. Ecol. Lett., 5: 558-567.

Dunne, J. A., Williams, R. J., and Martinez, N. D. (2004). Network structure and robustness of marine food webs. Mar. Ecol. Prog. Ser., 273: 291-302.

Dunne, J.A., Lafferty, K.D., Dobson, A.P., Hechinger, R.F., Kuris, A.M., Martinez, N. D., et al. 2013. Parasites affect food web structure primarily through increased diversity and complexity. PLoS Biol, 11: e1001579. doi:10.1371/journal.pbio.1001579.

Durbin, E.G., Casas, M.C., and Rynearson, T.A. 2011. Copepod feeding and digestion rates using prey DNA and qPCR. J. Plankton Res., 34: 72-82.

Eitzinger, B., Micic, A., Körner, M., Traugott, M., and Scheu, S. 2013. Unveiling soil food web links: new PCR assays for detection of prey DNA in the gut of soil arthropod predators. Soil Biol. Biochem., 57: 943-945.

Elias, M., Fontaine, C., and van Veen, F.J.F. 2013 Evolutionary history and ecological processes shape a local multilevel antagonistic network. Curr. Biol., 23: 1355-1359.

Elton, C.S. 1927. Animal Ecology. The MacMillan Company, New York.

Emrich, M.A., Clare, E.L., Symondson, W.O.C., Koenig, S.E., and Fenton, M.B. 2014. Resource partitioning by insectivorous bats in Jamaica. Mol. Ecol., 23: 3648-3656.

Evans, D.M., Pocock, M.J.O., Brooks, J., and Memmott, J. 2011 Seeds in farmland food-webs: Resource importance, distribution and the impacts of farm management. Biol. Conserv., 144: 2941- 610

Evans, D.M., Pocock, M.J.O., and Memmott, J. 2013 The robustness of a network of ecological networks to habitat loss. Ecol.Lett., 16: 844-852.

Evans, D.M., Kitson, J.N., Lunt, D.H., Straw, N.A., and Pocock, M.J.O. 2016. Merging DNA metabarcoding and ecological network analysis to understand and build resilient terrestrial ecosystems. Functional Ecology, [in press] doi:10.1111/1365-2435.12659

Fontaine, C., and Thébault, E. 2015. Comparing the conservatism of ecological interactions in plantpollinator and plant-herbivore networks. Popul. Ecol., 57: 29-36. 
Fontaine, C., Guimaraes, P.R.,Jr, Kefi, S., Loeuille, N., Memmott, J., van der Putten, W.H., et al. 2011 The ecological and evolutionary implications of merging different types of networks. Ecol. Lett., 14: $1170-1181$.

Forister, M.L., Novotny, V., Panorska, A.K., Baje, L., Basset, Y., Butterill, P.T., et al. 2015. The global distribution of diet breadth in insect herbivores. Proc. Natl. Acad. Sci. U.S.A., 112: 442-447.

Fort, H., Vázquez, D.P., and Lan, B.L. 2015. Abundance and generalisation in mutualistic networks: solving the chicken-and-egg dilemma. Ecol. Lett., 19: 4-11. doi:10.1111/ele.12535.

Frost, B.W. 1972. Effects of size and concentration of food particles on the feeding behavior of the marine planktonic copepod Calanus pacificus. Limnol. Oceanogr., 17: 805-815.

Fuhrman, J.A., Cram, J.A., and Needham, D.M. 2015. Marine microbial community dynamics and their ecological interpretation. Nature Rev. Microbiol., 13: 133-146. doi:10.1038/nrmicro3417.

Furlong, M.J. 2015. Knowing your enemies: Integrating molecular and ecological methods to assess the impact of arthropod predators on crop pests. Insect Science, 22: 6-19.

Gaston, K. 2000 Global patterns in biodiversity. Nature, 405: 220-227.

García-Robledo, C., Erickson, D.L., Staines, C.L., Erwin, T.L., and Kress, W.J. $2013 a$ Tropical plantherbivore networks: reconstructing species interactions using DNA barcodes. PloS ONE, 8: e52967.

García-Robledo, C., Kuprewicz, E.K., Staines, C.L., Kress, W.J., and Erwin, T.L. 2013b. Using a comprehensive DNA barcode library to detect novel egg and larval host plant associations in a Cephaloleia rolled-leaf beetle (Coleoptera: Chrysomelidae). Biol. J. Linn. Soc. Lond., 110: 189198.

Goldwasser, L., and Roughgarden, J., 1997. Sampling effects and the estimation of food-web properties. Ecology, 78: 41-54.

González-Varo, J. P., Arroyo, J. M., and Jordano, P. 2014. Who dispersed the seeds? The use of DNA barcoding in frugivory and seed dispersal studies. Methods Ecol. Evol., 5: 806-814.

Gravel, D., Poisot, T., Albouy, C., Velez, L., and Mouillot, D. 2013. Inferring food web structure from predator-prey body size relationships. Methods Ecol. Evol., 4: 1083-1090. 
Greenstone, M.H., Payton, M.E., Weber, D.C., Simmons, A.M. 2014. The detectability half-life in arthropod predator-prey research: what it is, why we need it, how to measure it, and how to use it. Mol. Ecol. 23: 3799-3813. doi:10.1111/mec.12552.

Harwood, J.D., and Obrycki, J.J. 2005 Quantifying aphid predation rates of generalist predators in the field. Eur. J. Entomol., 102: 335-350.

Hastings, A., McCann, K.S., and de Ruiter, P.C. (Editors). 2016. Theory of food webs. Theor. Ecol., 9: 1115.

Hauff, M.J., Llopiz, J.K., Blanco-Bercial, L., and Bucklin, A. 2015 Gelatinous prey of fishes: qPCR analysis of an overlooked pathway in mesopelagic foodwebs. In Proceedings of the ASLO Aquatic Sciences Meeting, Granada, Spain, 22-27 February 2015. Association for the Sciences of Limnology and Oceanography, Granada, Spain. p. 104.

Havens, K.E. 1992. Scale and structure in natural food webs. Science, 257: 1107-1109.

Havens, K.E. 2002. Zooplankton structure and potential food web interactions in the plankton of a subtropical chain-of-lakes. Scientific World J., 2: 926-942.

Hebert, P.D., Ratnasingham, S., and de Waard, J.R. 2003. Barcoding animal life: cytochrome c oxidase subunit 1 divergences among closely related species. Proc. R. Soc. B Biol. Sci., 270(Suppl 1): S96S99.

Hebert, P.D., Penton, E.H., Burns, J.M., Janzen, D.H., and Hallwachs, W. 2004. Ten species in one: DNA barcoding reveals cryptic species in the neotropical skipper butterfly Astraptes fulgerator. Proc. Natl. Acad. Sci. U.S.A., 101: 14812-14817.

Hechinger, R.F., Lafferty, K.D., McLaughlin, J.P., Fredensborg, B., Huspeni, T.C., et al. 2011 Food webs including parasites, biomass, body sizes, and life-stages for three California/Baja California estuaries. Ecology, 92: 791.

Heidemann, K., Hennies, A., Schakowske, J., Blumenberg, L., Ruess, L., Scheu, S., and Maraun, M. 2014. Free-living nematodes as prey for higher trophic levels of forest soil food webs. Oikos, 123: 11991211.

Henneman, M.L., and Memmott, J. 2001. Infiltration of a Hawaiian community by introduced biological control agents. Science, 293: 1314-1316. 
Hendrich, L., Morinière, J., Haszprunar, G., Hebert, P.D., Hausmann, A., Köhler, F., and Balke, M. 2015. A comprehensive DNA barcode database for Central European beetles with a focus on Germany: adding more than 3500 identified species to BOLD. Mol. Ecol. Resour., 15: 795-818. doi: $10.1111 / 1755-0998.12354$

Hoekman, D., Dreyer, J., Jackson, R.D., Townsend, P.A., and Gratton, C. 2011. Lake to land subsidies: Experimental addition of aquatic insects increases terrestrial arthropod densities. Ecology 92 : $2063-2072$.

Hollingsworth, P.M. 2011 Refining the DNA barcode for land plants. Proc. Natl. Acad. Sci. U.S.A., 108: $19451-19452$.

Hollingsworth, P.M., Graham, S.W., and Little, D.P. 2011 Choosing and using a plant DNA barcode. PLoS ONE, 6: e19254.

Hrček, J., and Godfray, H.C.J. 2015 What do molecular methods bring to host-parasitoid food webs? Trends Parasitol., 31: 30-35.

Hrček, J.A.N., Miller, S.E., Quicke, D.L., and Smith, M. 2011. Molecular detection of trophic links in a complex insect host-parasitoid food web. Mol. Ecol. Resour., 11: 786-794.

Hrček, J.A.N., Miller, S.E., Whitfield, J.B., Shima, H., and Novotny, V. 2013. Parasitism rate, parasitoid community composition and host specificity on exposed and semi-concealed caterpillars from a tropical rainforest. Oecologia, 173: 521-532.

Hu, S., Guo, Z., Li, T., Xu, C., Huang, H., Liu, S., and Lin, S. 2015. Molecular analysis of in situ diets of coral reef copepods: evidence of terrestrial plant detritus as a food source in Sanya Bay, China. J. Plankton Res., 37: 363-371. doi:10.1093/plankt/fbv014.

Hubert, N., Espiau, B., Meyer, C. and Planes, S. (2015), Identifying the ichthyoplankton of a coral reef using DNA barcodes. Mol. Ecol. Resour., 15: 57-67. doi: 10.1111/1755-0998.12293

Huxham, M., Beany, S., and Raffaelli, D. 1996 Do parasites reduce the chances of triangulation in a real food web? Oikos, 76: 284-300.

Ings, T.C., Montoya, J.M., Bascompte, J., Blüthgen, N., Brown, L., Dormann, C.F., et al. 2009. Ecological networks - beyond food webs. J. Anim. Ecol., 78: 253-269. 
Jarman, S.N., Gales, N.J., Tierney, M., Gill, P.C., and Elliott, N.G. 2002. A DNA-based method for identification of krill species and its application to analysing the diet of marine vertebrate predators. Mol. Ecol., 11: 2679-2690.

Ji, Y., Ashton, L., Pedley, S.M., Edwards, D.P., Tang, Y., Nakamura, A., et al. 2013 Reliable, verifiable and efficient monitoring of biodiversity via metabarcoding. Ecol. Lett., 16: 1245-1257.

Jo, H., Gim, J.A., Jeong, K.S., Kim, H.S., and Joo, G.J. 2014. Application of DNA barcoding for identification of freshwater carnivorous fish diets: Is number of prey items dependent on size class for Micropterus salmoides? Ecol. Evol., 4: 219-229.

Kaartinen, R., Stone, G.N., Hearn, J., Lohse, K., and Roslin, T. 2010. Revealing secret liaisons: DNA barcoding changes our understanding of food webs. Ecol. Entomol., 35: 623-638.

Kaartinen, R., and Roslin, T. 2011. Shrinking by numbers: Landscape context affects the species composition but not the quantitative structure of local food webs. J. Anim. Ecol., 80: 622-631.

Kéfi, S., Berlow, E.L., Wieters, E.A., Navarrete, S.A., Petchey, O.L., Wood, S.A., et al. 2012 More than a meal... integrating non-feeding interactions into food webs. Ecol. Lett., 15: 291-300.

King, R.A., Read, D. S., Traugott, M., and Symondson, W.O.C. 2008. Molecular analysis of predation: a review of best practice for DNA-based approaches. Mol. Ecol., 17: 947-963.

Kitching, R. 2004 Those d... elusive food webs. Trends Ecol. Evol., 19: 294-295.

Kitson, J.J.N., Warren, B.H., Florens, F.B.V., Baider, C., Strasberg, D., and Emerson, B.C. 2013 Molecular characterization of trophic ecology within an island radiation of insect herbivores (Curculionidae: Entiminae: Cratopus). Mol. Ecol., 22: 5441-5455.

Kajtoch, Ł., Kubisz, D., Heise, W., Mazur, M.A., and Babik, W. 2015. Plant-herbivorous beetle networks: molecular characterization of trophic ecology within a threatened steppic environment. Mol. Ecol., 24: $4023-4038$.

Knowlton, N. 1993. Sibling species in the sea. Annu. Rev. Ecol. Syst. 24: 189-216.

Kolb, G.S., Jerling, L., and Hambäck, P.A. 2010. The impact of cormorants on plant-arthropod food webs on their nesting islands. Ecosystems 13: 353-366. 
Kress, W.J., Erickson, D.L., Jones, F.A., Swenson, N.G., Perez, R., Sanjur, O., and Bermingham, E. 2009. Plant DNA barcodes and a community phylogeny of a tropical forest dynamics plot in Panama. Proc. Natl. Acad. Sci. U.S.A., 106: 18621-18626.

Kress, W.J., García-Robledo, C., Uriarte, M., and Erickson, D.L. 2015. DNA barcodes for ecology, evolution, and conservation. Trends Ecol. Evol., 30: 25-35.

Kruger, F., Clare, E.L., Symondson, W.O.C., Keišs, O., and Pētersons, G. 2014 Diet of the insectivorous bat Pipistrellus nathusii during autumn migration and summer residence. Mol. Ecol., 23: 3672-3683.

Kuzmina, M.L., Johnson, K.L., Barron, H.R., and Hebert, P.D.N. 2012 Identification of the vascular plants of Churchill, Manitoba, using a DNA barcode library. BMC Ecol., 12: 25.

Lang, B., Rall, B. C., Scheu, S., and Brose, U. 2014. Effects of environmental warming and drought on sizestructured soil food webs. Oikos, 123: 1224-1233.

Lavandero, B., and Tylianakis, J.M. 2013. Genotype matching in a parasitoid-host genotypic food web: an approach for measuring effects of environmental change. Mol. Ecol., 22: 229-238.

Layman, C.A., Giery, S.T., Buhler, S., Rossi, R., Penland, T., Henson, M. N., et al. 2015. A primer on the history of food web ecology: Fundamental contributions of fourteen researchers. Food Webs, 4 : $14-24$.

Leal, M.C., Ferrier-Pagès, C., Calado, R., Thompson, M.E., Frischer, M.E., and Nejstgaard, J.C. 2014 a. Coral feeding on microalgae assessed with molecular trophic markers. Mol. Ecol., 23: 3870-3876.

Leal, M.C., Nejstgaard, J.C., Calado, R., Thompson, M.E., and Frischer, M.E. 2014. Molecular assessment of heterotrophy and prey digestion in zooxanthellate cnidarians. Mol. Ecol., 23: 3838-3848.

Legagneux, P., Gauthier, G., Berteaux, D., Bety, J., Cadieux, M.C., et al. 2012. Disentangling trophic relationships in a High Arctic tundra ecosystem through food web modeling. Ecology 93: 17071716.

Leray, M., and Knowlton, N. 2015. DNA barcoding and metabarcoding of standardized samples reveal patterns of marine benthic diversity. Proc. Natl. Acad. Sci. U.S.A. 112: 2076-2081. doi:10.1073/pnas.1424997112. 
Leray, M., Boehm, J.T.,Mills, S.C., and Meyer, C.P. 2012. Moorea BIOCODE barcode library as a tool for understanding predator-prey interactions: insights into the diet of common predatory coral reef fishes. Coral Reefs 31: 383-388. doi:10.1007/s00338-011-0845-0.

Leray, M, Yang, J.Y., Meyer, C.P. Mills, S.C., Agudelo, N., Ranwez, V., et al. 2013. A new versatile primer set targeting a short fragment of the mitochondrial COI region for metabarcoding metazoan diversity: application for characterizing coral reef fish gut contents. Front. Zool. 10: 34.

Leray, M., Meyer, C.P., and Mills, S.C. 2015 Metabarcoding dietary analysis of coral dwelling predatory fish demonstrates the minor contribution of coral mutualists to their highly partitioned, generalist diet. PeerJ, 3: e1047. doi.org/10.7717/peerj.1047

Lewinsohn, T and Roslin, T. 2008. Four ways toward tropical herbivore megadiversity. Ecol. Lett., 11: 398416.

Linard, B., Crampton-Platt, A., Timmermans, M.J., and Vogler, A.P. 2015. Metagenome skimming of insect specimen pools: potential for comparative genomics. Genome Biol. Evol. 7: 1474-1489.

Lindeque, P.K., Parry, H.E., Harmer, R.A., Somerfield, P.J., and Atkinson, A. 2013. Next generation sequencing reveals the hidden diversity of zooplankton assemblages. PLoS ONE, 8: e81327. doi:10.1371/journal.pone.0081327.

Link, J. 2002. Does food web theory work for marine ecosystems? Mar. Ecol. Prog. Ser. 230: 1-9

Lurgi, M., Montoya, D., and Montoya, J.M. 2015. The effects of space and diversity of interaction types on the stability of complex ecological networks. Theoretical Ecology, doi:10.1007/s12080-015-0264$\mathrm{x}$.

Maloy, A.P., Culloty S.C., Slater J.W. 2013. Dietary analysis of small planktonic consumers: a case study with marine bivalve larvae. J. Plankton Res., 35: 866-876.

Majaneva, S. 2014. Understanding the biodiversity and ecological importance of ctenophores - Lessons from Arctic and Baltic Mertensia ovum. W. \& A. de Nottbeck Foundation Sci. Rep., 41: 1-74 [online]. Available from http://urn.fi/URN:ISBN:978-952-67851-6-5. [accessed 27 December 2015].

Majaneva, S., Setälä, O., Gorokhova, E., and Lehtiniemi, M. 2014. Feeding of the Arctic ctenophore Mertensia ovum in the Baltic Sea: evidence of the use of microbial prey. J. Plankton Res., 36: 91103. 
Martinez, N.D. 1991 Artifacts or attributes? Effects of resolution on the Little Rock Lake food web. Ecol. Monogr., 61: 367-392.

Martinez, N.D. 1993a. Effects of resolution on food web structure. Oikos, 66: 403-412.

Martinez, N.D. 1993b. Effect of scale on food web structure. Science 260: 242-243

Martinez, N.D. 1994. Scale-dependent constraints on foodweb structure. Am. Nat. 144: 935-953

McCann, K. 2007. Protecting biostructure. Nature, 446: 29.

McCann, K., Hastings, A., and Huxel, G.R. 1998. Weak trophic interactions and the balance of nature. Nature, 395: 794-798.

McCann, K. 2014. The adaptive capacity of aquatic food webs. In 144th Annual Meeting of the American Fisheries Society. Québec City, Canada. August 17-21, 2014. American Fisheries Society. Québec City, Canada. p. 173.

McCliment, E.A., Nelson, C.E., Carlson, C.A., Alldredge, A.L., Witting, J., and Amaral-Zettler, L.A. 2012. An all-taxon microbial inventory of the Moorea coral reef ecosystem. ISME J., 6: 309-319.

Méheust, E., Alfonsi, E., Le Ménec, P., Hassani, S., and Jung, J.L. 2015. DNA barcoding for the identification of soft remains of prey in the stomach contents of grey seals (Halichoerus grypus) and harbour porpoises (Phocoena phocoena). Mar. Biol. Res., 11: 385-395.

Mellbrand, K., and Hambäck, P.A. 2010. Coastal niches for terrestrial predators: a stable isotope study. Can. J. Zool., 88: 1077-1085.

Mellbrand, K., Östman, Ö., and Hambäck, P. A. 2010. Effects of subsidized spiders on coastal food webs in the Baltic Sea area. Basic. Appl. Ecol., 11: 450-458.

Memmott, J. 2009. Food webs: a ladder for picking strawberries or a practical tool for practical problems? Phil. Trans. R. Soc. B, 364: 1693-1699.

Montoya, D., Rogers, L., and Memmott, J. 2012 Emerging perspectives in the restoration of biodiversity based ecosystem services. Trends Ecol. Evol., 27: 666-672.

Morales-Castilla, I., Matias, M.G., Gravel, D., and Araújo, M.B. 2015. Inferring biotic interactions from proxies. Trends Ecol. Evol., 30: 347-356. 
Moran, Z., Orth, D.J., Schmitt, J.D., Hallerman, E.M., and Aguilar, R. 2015. Effectiveness of DNA barcoding for identifying piscine prey items in stomach contents of piscivorous catfishes. Environ. Biol. Fishes, 99: 161-167.

Morlon, H., Kefi, S., and Martinez, N.D. 2014. Effects of trophic similarity on community composition. Ecol. Lett., 17: 1495-1506

Morris, R. J., Gripenberg, S., Lewis, O.T., and Roslin, T. 2014. Antagonistic interaction networks are structured independently of latitude and host guild. Ecol. Lett., 17: 340-349.

Morris, R.J., Lewis, O.T., and Godfray, H.C.J. 2004 Experimental evidence for apparent competition in a tropical forest food web. Nature, 428: 310-313.

Morris, R.J., Lewis, O.T., and Godfray, H.C.J. 2005 Apparent competition and insect community structure: towards a spatial perspective. Ann. Zool. Fenn., 42: 449-462.

Mostajir, B., Amblard, C., Buffan-Dubau, E., De Wit, R., Lensi, R., and Sime-Ngando, T. 2015. Microbial food webs in aquatic and terrestrial Ecosystems. In Environmental Microbiology: Fundamentals and Applications. Edited by J.-C. Bertrand, P. Caumette, P. Lebaron, R. Matheron, P. Normand, and T. Sime-Ngando. Springer, Netherlands. pp. 485-509.

Mouritsen, K.N., Poulin, R., McLaughlin, J.P., and Thieltges, D.W. 2011 Food web including metazoan parasites for an intertidal ecosystem in New Zealand. Ecology 92: 2006.

Müller, C.B., Adriaanse, I.C.T., Belshaw, R., and Godfray, H.C.J. 1999 The structure of an aphid-parasitoid community. J. Anim. Ecol., 68: 346-370.

Murray, D.C., Bunce, M., Cannell, B.L., Oliver, R., Houston, J., White, N.E., et al. 2011. DNA-based faecal dietary analysis: a comparison of qPCR and high throughput sequencing approaches. PLoS ONE, 6: e25776. doi:10.1371/journal.pone.0025776.

Nejstgaard, J.C., Frischer, M.E., Raule, C.L., Gruebel, R., Kohlberg, K.E., and Verity, P.G. 2003. Molecular detection of algal prey in copepod guts and fecal pellets. Limnol. Oceanogr. Methods, 1: 29-38.

Nejstgaard, J.C., Frischer, M.E., Simonelli, P., Troedsson, C., Brakel, M., Adiyaman, F., et al. 2008. Quantitative PCR to estimate copepod feeding. Mar. Biol., 153: 565-577. 
Novotny, V., Miller, S.E., Baje, L., Balagawi, S., Basset, Y., Cizek, L., et al. 2010. Guild-specific patterns of species richness and host specialization in plant-herbivore food webs from a tropical forest. J. Anim. Ecol., 79: 1193-1203.

Nyffeler, M. 1999. Prey selection of spiders in the field. J. Arachnol., $27: 317-324$.

Nyman, T., Bokma, F., and Kopelke, J.P. 2007. Reciprocal diversification in a complex plant-herbivoreparasitoid food web. BMC Biol., 5: 49.

Nyman, T., Leppänen, S.A., Várkonyi, G., Shaw, M.R., Koivisto, R., Barstad, T.E., et al. 2015. Determinants of parasitoid communities of willow-galling sawflies: habitat overrides physiology, host plant and space. Mol. Ecol., 24: 5059-5074.

O’Rorke, R., Lavery, S., and Jeffs, A.G. 2012a. PCR enrichment techniques to identify the diet of predators. Mol. Ecol. Res., 12: 5-17.

O’Rorke, R., Lavery, S., Chow, S., Takeyama, H., Tsai, P., Beckley, L.E., et al. 2012b Determining the diet of larvae of western rock lobster (Panulirus cygnus) using highthroughput DNA sequencing techniques. PLoS ONE, 7: e42757.

O’Rorke, R., Jeffs, A.G., Fitzgibbon, Q.P., Chow, S., and Lavery, S. 2013. Extracting DNA from whole organism homogenates and the risk of false positives in PCR based diet studies: A case study using spiny lobster larvae. J. Exp. Mar. Biol. Ecol., 441: 1-6.

O’Rorke, R., Lavery, S.D., Wang, M., Nodder, S.D. and Jeffs, A. G. 2014. Determining the diet of larvae of the red rock lobster (Jasus edwardsii) using high-throughput DNA sequencing techniques. Mar. Biol., 161: 551-563.

Olsen, B.R., Troedsson, C., Hadziavdic, K., Pedersen, R.B., and Rapp, H.T. 2014. A molecular gut content study of Themisto abyssorum (Amphipoda) from Arctic hydrothermal vent and cold seep systems. Mol. Ecol., 23: 3877-3889.

Orford, K.A., Vaughan, I.P., and Memmott, J. 2015. The forgotten flies: the importance of non-syrphid Diptera as pollinators. Proc. R. Soc. B Biol. Sci., 282: 20142934.

Padilla, D.K., and Savedo, M.M. 2013. A systematic review of phenotypic plasticity in marine invertebrate and plant systems. Adv. Mar. Biol., 65: 67-94. 
Paetzold, A., Lee, M., and Post, D.M. 2008. Marine resource flows to terrestrial arthropod predators on a temperate island: the role of subsidies between systems of similar productivity. Oecologia 157: $653-659$.

Paine, R.T., 1988. Food web: road maps of interactions or grist for theoretical development? Ecology, 69: $1648-1654$.

Papadopoulou, A., Taberlet, P., and Zinger, L. 2015. Metagenome skimming for phylogenetic community ecology: a new era in biodiversity research. Mol. Ecol., 24: 3515-3517.

Paula. D.P., Linard, B., Andow, D.A., Sujii, E.R., Pires, C.S.S., Vogler A.P. 2015. Detection and decay rates of prey and prey symbionts in the gut of a predator through metagenomics. Mol Ecol Resour. 15: 880-892. doi:10.1111/1755-0998.12364.

Pearse, I.S., and Altermatt, F. 2013. Extinction cascades partially estimate herbivore losses in a complete Lepidoptera-plant food web. Ecology, 94: 1785-1794.

Pegg, G.G., Sinclair, B., Briskey, L., and Aspden, W.J. 2006. MtDNA barcode identification of fish larvae in the southern Great Barrier Reef, Australia. Sci. Mar., 70: 7-12.

Pentinsaari, M., Hebert, P.D.N., and Mutanen, M. 2014 Barcoding beetles: a regional Survey of 1872 species reveals high identification success and unusually deep interspecific divergences. PLoS ONE, 9: e108651. doi:10.1371/journal.pone.0108651.

Peralta, G., Frost, C.M., Didham, R.K., Varsani, A., and Tylianakis, J.M. 2015. Phylogenetic diversity and co-evolutionary signals among trophic levels change across a habitat edge. J. Anim. Ecol., 84: 364 372.

Petchey, O.L., Beckerman, A.P., Riede, J.O., and Warren, P.H. 2008. Size, foraging, and food web structure. Proc. Natl. Acad. Sci. U.S.A., 105: 4191-4196.

Phillips, D.L., and Eldridge, P.M. 2006. Estimating the timing of diet shifts using stable isotopes. Oecologia, 147: 195-203.

Pinol, J., San Andrés, V., Clare, E. L., Mir, G., and Symondson, W. O. C. 2014. A pragmatic approach to the analysis of diets of generalist predators: the use of next-generation sequencing with no blocking probes. Mol. Ecol. Resour., 14: 18-26. 
Pocock, M. J., Evans, D. M., and Memmott, J. 2012. The robustness and restoration of a network of ecological networks. Science, 335: 973-977.

Poisot, T., Canard, E., Mouillot, D., Mouquet, N., and Gravel, D. 2012. The dissimilarity of species interaction networks. Ecol. Lett., 15: 1353-1361.

Poisot, T., Stouffer, D. B., and Gravel, D. 2015. Beyond species: why ecological interaction networks vary through space and time. Oikos, 124: 243-251.

Polis, G.A., and Winemiller, K.O. 1996. Food webs: integration of patterns and dynamics. Springer Science \& Business Media.

Polis, G.A., Anderson, W.B., and Holt, R.D. 1997. Toward an integration of landscape and food web ecology: The dynamics of spatially subsidized food webs. Annu. Rev. Ecol. Evol. Syst., 28: 289316.

Pompanon, F., Deagle, B.E. Symondson, W.O.C., Brown, D.S., Jarman, S.N., and Taberlet, P. 2012. Who is eating what: diet assessment using next generation sequencing. Mol. Ecol., 21: 1931-1950.

Post, D.M. 2002. The long and short of food-chain length.Trends Ecol. Evol. 17: 269-277.

Post, D.M. and Takimoto, G. 2007. Proximate structural mechanisms for variation in food-chain length. Oikos 116: 775-782.

Post, D.M., Pace, M.L., and Hairston, N.G. 2000. Ecosystem size determines food-chain length in lakes. Nature 405: 1047-1049.

Radulovici, A.E., Archambault, P., and Dufresne, F. 2010. DNA barcodes for marine biodiversity: moving fast forward? Diversity, 2: 450-472.

Rafferty, N.E., and Ives, A.R. 2013 Phylogenetic trait-based analyses of ecological networks. Ecology, 94: 2321-2333.

Ratnasingham, S., and Hebert, P.D.N. 2007. BOLD: the barcode of life data system (www.barcodinglife.org). Mol. Ecol. Notes, 7: 355-364.

Ratnasingham, S., and Hebert, P.D.N. 2013. A DNA-based registry for all animal species: the Barcode Index Number (BIN) system. PloS ONE, 8: e66213. 
Razgour, O., Clare, E.L. Zeale, M.R.K., Hanmer, J., Schnell, I.B., Rasmussen, M., et al. 2011. Highthroughput sequencing offers insight into mechanisms of resource partitioning in cryptic bat species. Ecol. Evol., 1: 556-570.

Rooney, N. and McCann, K.S. 2012. Integrating food web diversity, structure and stability. Trends Ecol. Evol., 27: 40-46.

Roslin, T., Várkonyi, G., Koponen, M., Vikberg, V., and Nieminen, M. 2013. Species-area relationships across four trophic levels - decreasing island size truncates food chains. Ecography 37: 443-453.

Saarela, J.M., Sokoloff, P.C., Gillespie, L.J., Consaul, L.L., and Bull, R.D. 2013. DNA barcoding the Canadian arctic flora: core plastid barcodes (rbcL + matK) for 490 vascular plant species. PLoS ONE, 8: e77982. doi:10.1371/journal.pone.0077982.

Sabo, J.L., and Power, M.E. 2002a. River-watershed exchange: Effects of riverine subsidies on riparian lizards and their terrestrial prey. Ecology 83: 1860-1869.

Sabo, J.L., and Power, M.E. 2002b. Numerical response of lizards to aquatic insects and short-term consequences for terrestrial prey. Ecology 83: 3023-3036.

Sauve, A.M. C., Thébault, E., Pocock, M.J., and Fontaine, C. 2015. How plants connect pollination and herbivory networks and their contribution to community stability. Ecology, in press. doi:10.1890/15-0132.1.

Schleuning, M., Fründ, J., Klein, A.M., Abrahamczyk, S., Alarcon, R., Albrecht, M. et al. 2012. Specialization of mutualistic interaction networks decreases toward tropical latitudes. Curr. Biol., 22: $1925-1931$.

Schmidt, N.M., Hansen, L.H., Meltofte, H., Hansen, J., and Berg, T.B. 2012. BioBasis manual. Conceptual design and sampling procedures of the biological monitoring programme within Zackenberg Basic. 15th edition. Zackenberg Ecological Research Operations. Department of Bioscience, Aarhus University, Roskilde, Denmark.

Sheppard, S.K., Henneman, M.L., Memmott, J., and Symondson, W.O.C. 2004. Infiltration by alien predators into invertebrate food webs in Hawaii: a molecular approach. Mol. Ecol., 13: 2077-2088. 
Sheppard, S.K., Bell, J., Sunderland, K.D., Fenlon, J., Skervin, D., Symondson, W.O.C. 2005. Detection of secondary predation by PCR analyses of the gut contents of invertebrate generalist predators. Mol. Ecol., 14: 4461-4468

Sint, D., Thurner, I., Kaufmann, R., and Traugott, M. 2015. Sparing spiders: faeces as a non-invasive source of DNA. Front. Zool., 12: 3.

Smith, M.A., Woodley, N.E., Janzen, D.H., Hallwachs, W., and Hebert, P.D.N. 2006. DNA barcodes reveal cryptic host-specificity within the presumed polyphagous members of a genus of parasitoid flies (Diptera: Tachinidae). Proc. Natl. Acad. Sci. U.S.A., 103: 3657-3662.

Smith, M.A., Wood, D.M., Janzen, D.H., Hallwachs, W., and Hebert P.D.N. 2007. DNA barcodes affirm that 16 species of apparently generalist tropical parasitoid flies (Diptera, Tachinidae) are not all generalists. Proc. Natl. Acad. Sci. U.S.A., 104: 4967-4972.

Smith, M.A., Eveleigh, E.S., McCann, K.S., Merilo, M.T., McCarthy, P.C., and Van Rooyen, K.I. 2011. Barcoding a quantified food web: crypsis, concepts, ecology and hypotheses. PLoS ONE, 6 : e14424.

Soininen, E.M., Valentini, A. Coissac, E. Miquel, C. Gielly, L. Brochmann, C., et al. 2009. Analysing diet of small herbivores: the efficiency of DNA barcoding coupled with high-throughput pyrosequencing for deciphering the composition of complex plant mixtures. Front. Zool., 6: 16.

Soininen, E.M., Ehrich, D., Lecomte, N., Yoccoz, N.G., Tarroux, A. et al. 2014. Sources of variation in small rodent trophic niche: new insights from DNA metabarcoding and stable isotope analysis. Isotopes Environ. Health Stud., 50: 361-381.

Srinivasan, U.T., Dunne, J.A., Harte, J., and Martinez, N.D. 2007 Response of complex food webs to realistic extinction sequences. Ecology, 88: 671-682.

Staniczenko, P., Lewis, O.T., Jones, N.S., and Reed-Tsochas, F. 2010. Structural dynamics and robustness of food webs. Ecol. Lett., 13: 891-899.

Staudacher, K., Wallinger, C., Schallhart, N., and Traugott, M. 2011. Detecting ingested plant DNA in soilliving insect larvae. Soil Biol. Biochem., 43: 346-350. 
Stone, G.N., Lohse, K., Nicholls, J.A., Fuentes-Utrilla, P., Sinclair, F., Schönrogge, K., et al. 2012. Reconstructing community assembly in time and space reveals enemy escape in a Western Palearctic insect community. Curr. Biol., 22: 532-537.

Stouffer, D.B., and Bascompte, J. 2011. Compartmentalization increases food-web persistence. Proc. Natl. Acad. Sci. U.S.A., 108: 3648-3652.

Stouffer, D.B., Sales-Pardo, M., Sirer, M.I., and Bascompte, J. 2012. Evolutionary conservation of species' roles in food webs. Science, 335: 1489-1492.

Summerhayes, V. S., and C. S. Elton. 1923. Contributions to the ecology of Spitsbergen and Bear Island. J. Ecol., 11: 214-287.

Symondson, W. O. C. 2002. Molecular identification of prey in predator diets. Mol. Ecol. 11: 627-641.

Symondson, W.O., and Harwood, J.D. 2014. Special issue on molecular detection of trophic interactions: unpicking the tangled bank. Mol. Ecol., 23: 3601-3604.

Tack, A., Gripenberg, S., and Roslin, T. 2011. Can we predict indirect interactions from quantitative food webs? - An experimental approach. J. Anim. Ecol., 80: 108-118.

Tang, M., Hardman, C.J., Ji, Y.Q., Meng, G.L., Liu, S.L., Tan, M.H., et al. 2015. High-throughput monitoring of wild bee diversity and abundance via mitogenomics. Methods Ecol. Evol., 6: 10341043

Thebault, E., and Fontaine, C. 2010 Stability of ecological communities and the architecture of mutualistic and trophic networks. Science, 329: 853-856.

Thieltges, D.W., Reise, K., Mouritsen, K.N., McLaughlin, J.P., and Poulin, R. 2011. Food web including metazoan parasites for a tidal basin in Germany and Denmark. Ecology, 92: 2005.

Thomas, A. C., Jarman, S. N., Haman, K. H., Trites, A. W., and Deagle, B. E. 2014. Improving accuracy of DNA diet estimates using food tissue control materials and an evaluation of proxies for digestion bias. Mol. Ecol., 23: 3706-3718.

Thompson, R.M., Brose, U., Dunne, J.A., Hall, R.O., Hladyz, S., Kitching, R.L., et al. 2012. Food webs: reconciling the structure and function of biodiversity. Trends Ecol. Evol., 27: 689-697.

Thorson, G. 1950. Reproductive and larval ecology of marine bottom invertebrates Rev. Camb. Philos. Soc., 25: $1-45$ 
Toju, H. 2015. High-throughput DNA barcoding for ecological network studies. Popul. Ecol., 57: 37-51.

Toju, H., Guimarães, P.R., Olesen, J.M., and Thompson, J.N. 2014. Assembly of complex plant-fungus networks. Nat. Commun., 5: 5273 doi:10.1038/ncomms6273.

Trivedi, S., Aloufi, A.A., Ansari, A.A., and Ghosh, S.K. 2015. Role of DNA barcoding in marine biodiversity assessment and conservation: An update. Saudi J. Biol. Sci., doi:10.1016/j.sjbs.2015.01.001.

Trøjelsgaard, K., Jordano, P., Carstensen, D.W., and Olesen, J.M. 2015. Geographical variation in mutualistic networks: similarity, turnover and partner fidelity. Proc. R. Soc. B 282: 20142925. http://dx.doi.org/10.1098/rspb.2014.2925

Tylianakis, J.M., and Binzer, A. 2014. Effects of global environmental changes on parasitoid-host food webs and biological control. Biol. Control, 75: 77-86.

Tylianakis, J.M., Tscharntke, T., and Lewis, O.T. 2007. Habitat modification alters the structure of tropical host-parasitoid food webs. Nature, 445: 202-205.

Tylianakis, J.M., Didham, R.K., Bascompte, J., and Wardle, D.A. 2008 Global change and species interactions in terrestrial ecosystems. Ecol. Lett., 11: 1351-1363.

Valdez-Moreno, M., Quintal-Lizama, C., Gómez-Lozano, R., García-Rivas, MdC. 2012. Monitoring an alien invasion: DNA barcoding and the identification of lionfish and their prey on coral reefs of the Mexican Caribbean. PLoS ONE, 7: e36636. doi:10.1371/journal.pone.0036636.

Valentini, A., Pompanon, F., and Taberlet, P. 2009. DNA barcoding for ecologists. Trends Ecol. Evol., 24: $110-117$.

Valentini, A., Miquel, C. Nawaz, M.A., Bellemain, E., Coissac, E., Pompanon, F. et al. 2009. New perspectives in diet analysis based on DNA barcoding and parallel pyrosequencing: the trnL approach. Mol. Ecol. Resour., 9: 51-60.

Valverde, J., Gómez, J.M., and Perfectti, F. 2015. The temporal dimension in individual-based plant pollination networks. Oikos, in press. DOI: 10.1111/oik.02661

van Veen, F.J.F., Morris, R.J., and Godfray, H.C.J. 2006 Apparent competition, quantitative food webs, and the structure of phytophagous insect communities. Annu. Rev. Entomol., 51: 187-208 
van Veen, F.J.F., Muller, C.B., Pell, J.K., and Godfray, H.C.J. 2008 Food web structure of three guilds of natural enemies: predators, parasitoids and pathogens of aphids. J. Anim. Ecol., 77: 191-200.

Várkonyi, G., and Roslin, T. 2013. Freezing cold yet diverse - dissecting a High-Arctic parasitoid community associated with lepidopteran hosts. Can. Entomol., special issue 2: 193-218.

Vazquez, D.P., Chacoff, N.P., and Cagnolo, L. 2009 Evaluating multiple determinants of the structure of plant-animal mutualistic networks. Ecology, 90: 2039-2046.

de Vargas, C., Audic, S., Henry, N., Decelle, J., Mahé, F., Logares, R., et al. 2015. Eukaryotic plankton diversity in the sunlit ocean. Science, 348: 1261605. doi:10.1126/science.1261605.

Vesterinen, E.J. 2016. Food webs in the era of molecular revolution - like resolving the Gordian knot with a tricorder? Ph.D. thesis, Department of Biology, University of Turku, Finland [online]. Available from http://urn.fi/URN:ISBN:978-951-29-6301-0 [accessed 27 December 2015].

Vesterinen, E.J., Lilley, T., Laine, V.N., and Wahlberg, N. 2013. Next generation sequencing of fecal DNA reveals the dietary diversity of the widespread insectivorous predator Daubenton's bat (Myotis daubentonii) in Southwestern Finland. PLoS ONE, 8: e82168. doi:10.1371/journal.pone.0082168.

Vesterinen, E.J., Ruokolainen, L., Wahlberg, N., Peña, C., Roslin, T., Laine, V.N., Vasko, V., Sääksjärvi, I.E., Norrdahl, K., Lilley, T.M. What you need is what you eat? Prey selection of the bat Myotis daubentonii. Mol. Ecol., in press. doi:10.1111/mec.13564

Victor, B.C., Hanner, R., Shivji, M., Hyde, J., and Caldow, C. 2009 Identification of the larval and juvenile stages of the Cubera snapper, Lutjanus cyanopterus, using DNA barcoding. Zootaxa, 2215: 24-36.

Wallinger, C., Juen, A., Staudacher, K., Schallhart, N., Mitterrutzner, E., Steiner, E.-M., et al. 2012. Rapid plant identification using species- and group-specific primers targeting chloroplast DNA. PLoS ONE, 7: e29473. doi:10.1371/journal.pone.0029473.

Webb, K.E., Barnes, D.K.A., Clark, M.S., and Bowden, D.A. 2006. DNA barcoding: a molecular tool to identify Antarctic marine larvae. Deep Sea Res. II, 53: 1053-1060.

Williams, R. J., and Martinez, N. D. 2000. Simple rules yield complex food webs. Nature, 404: 180-183

Williams, R.J., and Martinez, N.D. 2008. Success and its limits among structural models of complex food webs. J. Anim. Ecol., 77: 512-519. 
Wirta, H.K., Hebert, P.D.N., Kaartinen, R., Prosser, S.W., Várkonyi, G., and Roslin, T. 2014. Complementary molecular information changes our perception of food web structure. Proc. Natl. Acad. Sci. U.S.A., 111: 1885-1890.

Wirta, H.K., Weingartner, E., Hambäck, P.A. and Roslin, T. 2015a. Extensive niche overlap among the dominant arthropod predators of the High Arctic. Basic. Appl. Ecol., 16: 86-98.

Wirta, H.K., Vesterinen, E.J., Hambäck, P.A., Weingartner, E., Rasmussen, C., Reneerkens, J., et al. $2015 b$. Exposing the structure of an Arctic food web. Ecol. Evol., 5: 3842-3856.

Wirta, H., Várkonyi, G., Rasmussen, C., Kaartinen, R., Schmidt, N.M., Hebert, P.D.N., et al. 2016. Establishing a community-wide DNA barcode library as a new tool for arctic research. Mol. Ecol. Resour., in press. doi:10.1111/1755-0998.12489

Yu, D.W., Ji, Y., Emerson, B.C., Wang, X., Ye, C., Yang, C., and Ding, Z. 2012. Biodiversity soup: metabarcoding of arthropods for rapid biodiversity assessment and biomonitoring. Methods Ecol. Evol., 3: 613-623.

Zander, C.D., Josten, N., Detloff, K.C., Poulin, R., McLaughlin, J.P., et al. 2011 Food web including metazoan parasites for a brackish shallow water ecosystem in Germany and Denmark. Ecology, 92: 2007. 


\section{Figure legends}

Fig. 1. The elements of a food web: The basic structure of a food web is dictated by how taxa (nodes) at different trophic levels (here three, corresponding to plant seeds, rodents and their ectoparasites) are connected by links (i.e. trophic interactions, feeding associations; shown by wedges in the figure). In the current figure, all links emerging from an example node are highlighted in black. In quantitative representations of food webs such as this, the abundance of each node and the frequency of each link is indicated by its width. As shown in Fig. 2, DNA barcodes offer an improved resolution to each of these components. Figure adapted from Pocock et al. 2012. Reprinted with permission from AAAS.

Fig. 2. Classical problems in food web reconstruction (left), with promising solutions offered by DNA barcodes (right):

A) Species are confounded into compound taxa or 'trophic species', making the structure of the web an artefact of inadequate resolution. As shown on the left, if the nodes of the web are not adequately resolved, we will misrepresent the linking structure around each. As shown on the right, DNA barcodes allow us to resolve cryptic specialized species within compound "generalist" species, thereby resolving the adequate structure of nodes and links.

B) Food webs are built from an eclectic mix of different types of data. As shown on the left, many influential descriptions of food web structure are based on a combination of direct feeding observations, expert opinion, patterns of co-occurrence and feeding trials. As shown on the right, molecular techniques offer the direct, commensurate, and repeatable identification of trophic links.

C) Different links are often differentially detectable by direct means, causing biases in link structure and quantification. As an example on the left, selective mortality of given parasitoid-host combinations (as shown in different colours) during the rearing stage may distort estimates of interaction frequencies (compare colour frequencies among caterpillars and parasitoids emerging). As shown on the right, direct sequencing of host remains in the gut contents of the adult parasitoid (called MAPL-AP by Wirta et al. 2014) and the parasitoid content of host larvae (MAP-HL) will allow us to circumvent the rearing phase altogether. 
D) Constraints on sample size limit descriptions and comparisons of food web structure. As illustrated on the left, the number of potential interactions (links) among a set of S species (blocks, ranging from only 2 to 32 in the food webs offered) increases in proportion to $\mathrm{S}^{2}$. Thus, adequate representations of food web structure will typically require (very) large sample sizes. As shown on the right, innovative molecular tagging (colour labels) of samples of food web nodes (tubes with colourful lids) as coupled to massive parallel sequencing (heaps of tagged sequences in front) yields new orders of sample size, and deep information on interaction structure.

E) Current studies are typically focused on specific modules within larger interaction webs, as detached from their true context of other types of ecological interactions. Shown on the left are specific types of interactions (those among seeds, rodents and ectoparasites), whereas on the right, the same submodule is plugged into the surrounding network of ecological networks. Here, the adoption of molecular methods as a general approach adaptable to a large number of specific interactions allows us to move towards full interaction networks. Picture credits: Panel E adapted from Pocock et al. 2012. Reprinted with permission from AAAS.

Fig. 3. [In Box 1] Food web reconstruction by DNA barcodes in the Zackenberg valley of Northeast Greenland. Here, panel A) shows the location of the study site in a global (inset) and Greenland perspective. Panel B) shows a picture of the local landscape, with the Zackenberg research station in front of the fjord. Panel C) shows a subset of the local food web as reconstructed by three different techniques: rearing; MAPL-AP (see Fig. 2C), and MAPL-HL (Fig. 2C). Blocks in the lower row represent hosts and blocks in the upper row represent parasitoids, with connecting lines identifying trophic links, and the width of the connector scaled to interaction frequency (cf. Fig. 1). The web shown here is based on a combination of all three methods. To highlight differences in the set of interactions detectable by each technique, we highlight links detected by a single methods in green (for links detected only by rearing), in blue (for links detected only by MAPL-AP), and in red (for links detected only by MAPL-HL). Panel C adapted from Wirta et al. 2014.

Fig. 4. [In Box 2] Food web reconstruction by DNA barcodes at the coral reef of Moorea, French Polynesia. Here, panel A) shows the location of Moorea in French Polynesia, in the middle of the Pacific Ocean (inset). 
Panel B) shows a picture of the reef habitat. Panel C) illustrates dietary partitioning among three predatory fish species as detected using metabarcoding dietary analysis. The taxonomic resolution provided by the metabarcoding approach highlights a complex interaction web and demonstrates that levels of trophic partitioning among coral reef fishes have likely been underestimated. Picture credits: Panel B photo by Heloise Rouze, Panel C adapted from Leray et al. 2015.

Fig. 5. Four molecular approaches proposed to quantify trophic link strength: A) Compound samples of DNA are amplified by general primers, and amplicons of each type assigned to a taxon as based on similarity with a reference library. The proportion of each amplicon type is then assumed proportional to the biomass of this taxon in the original bulk sample. B) Exact read frequencies are neglected, and molecular data converted to presence-absence data. In a sample of many droppings (or many gut contents, each treated as a replicate unit), the incidence of a given prey taxon is assumed to reflect rough consumption rates. C) Quantitative PCR (qPCR) is used to quantify the abundance of DNA present in the extract: Here, three fecal samples with different initial amounts of prey DNA (indicated by size of frog) cross the measurement threshold (dashed line) after different numbers of PCR cycles (X axis). D) DNA from the bulk sample is sequenced without any PCR step. The resultant sequences are aligned with a genomic reference library, and the proportion of DNA lining up with each reference genome is assumed to be proportional to the abundance of DNA present in the extract. 
Fig. 1

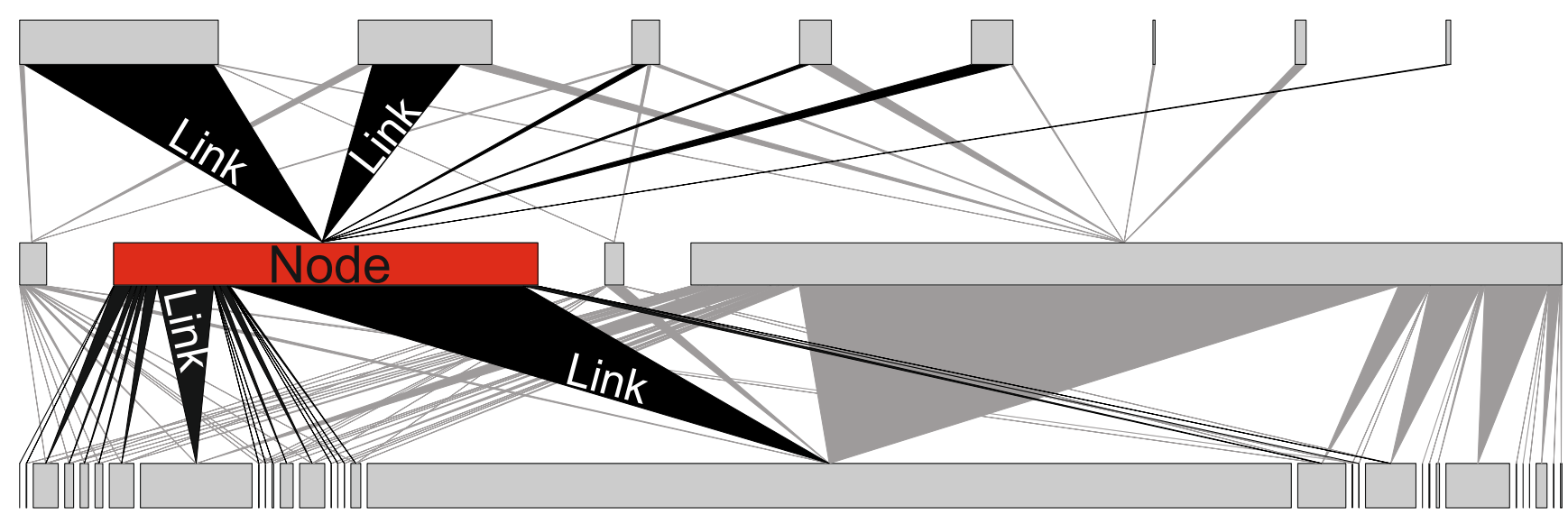



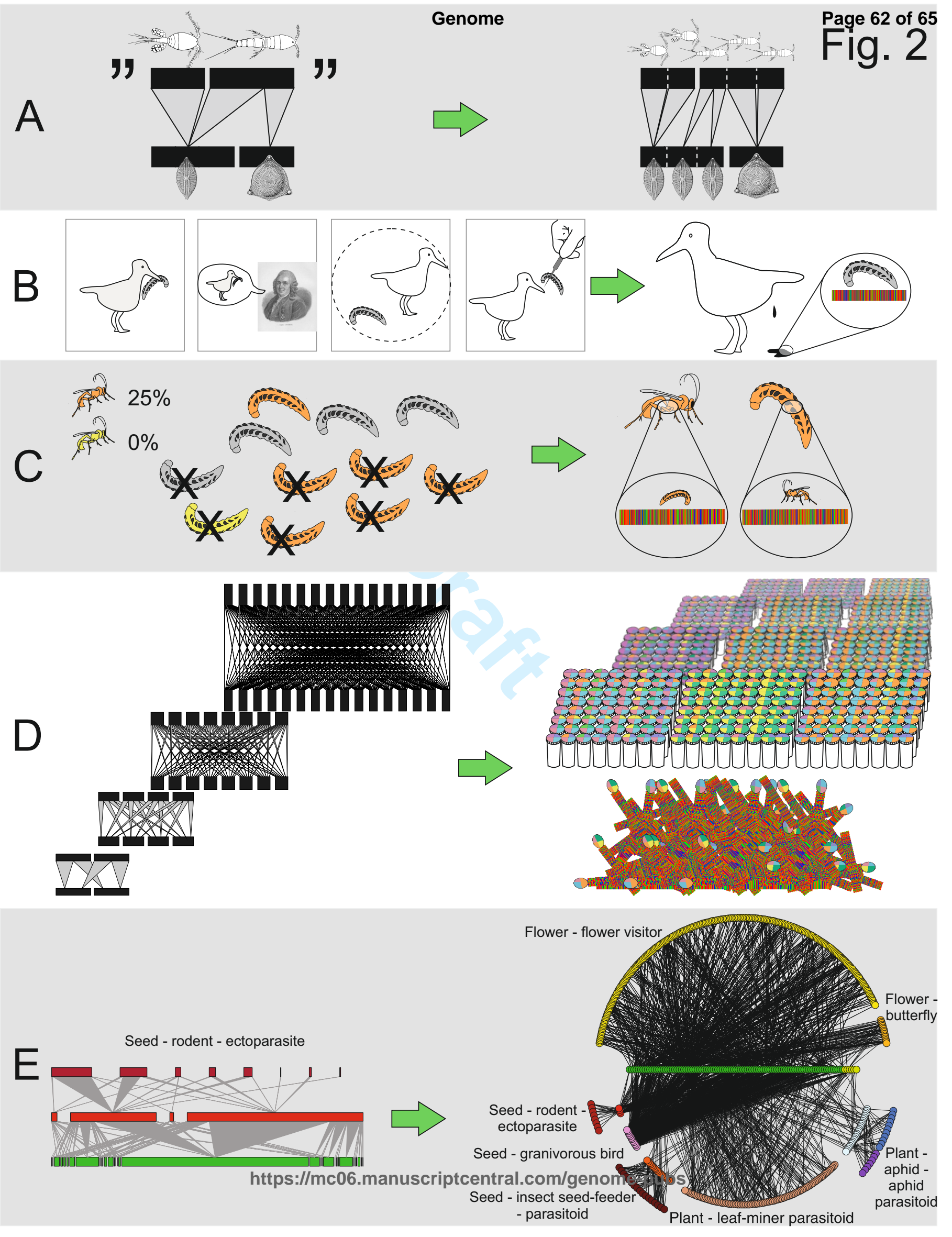
Fig. 3

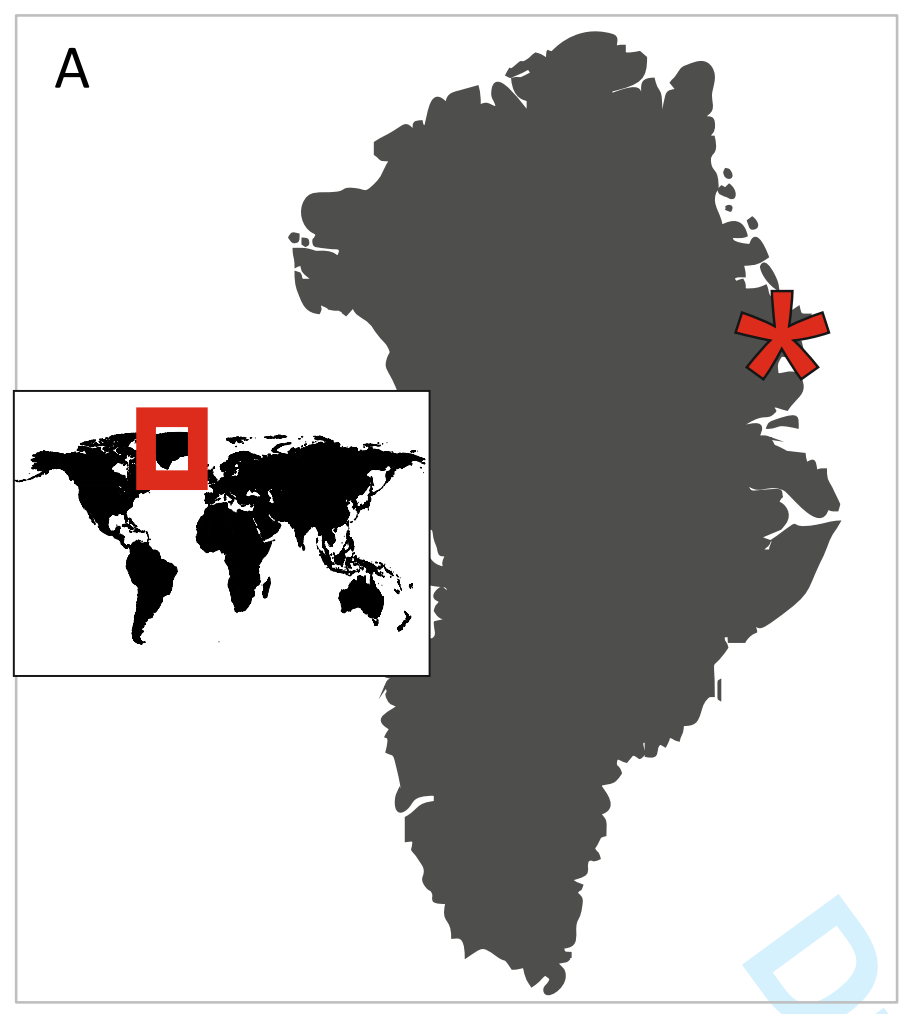

B

\section{C}

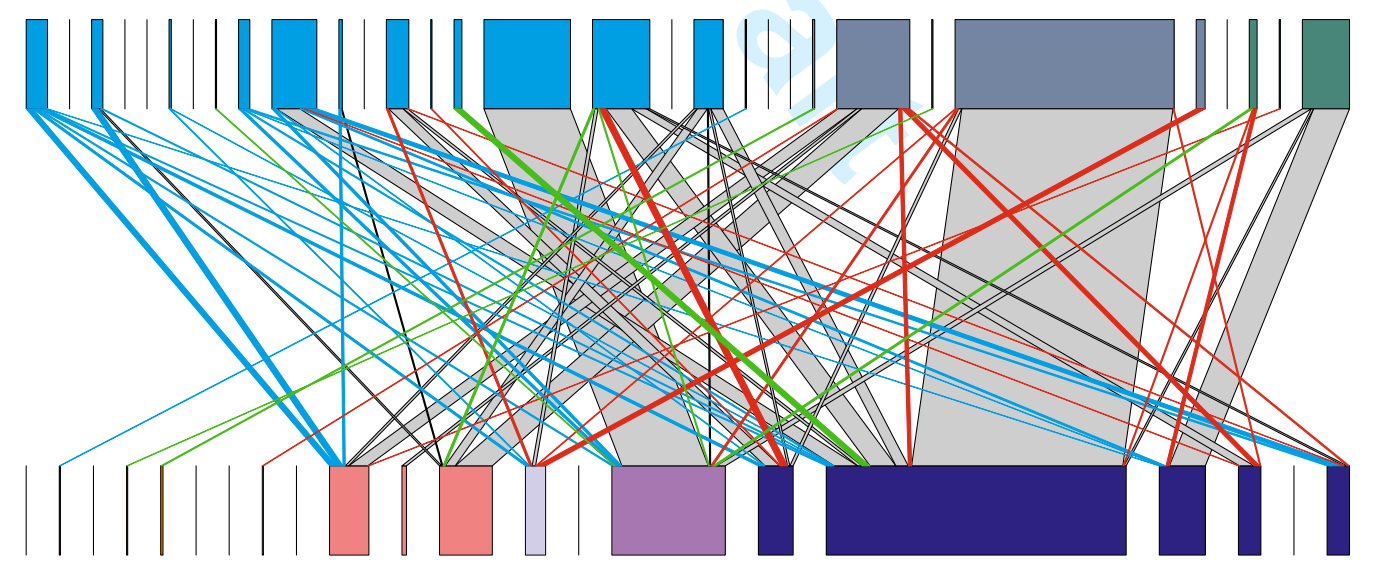

Ichneumonidae

Braconidae

Eulophidae

Tachinidae

Plutellidae

Tortricidae

Pterophoridae

Pyralidae

Crambidae

Pieridae

$\square$ Lycaenidae

Nymphalidae

Geometridae

Erebidae

Noctuidae 
Fig. 4

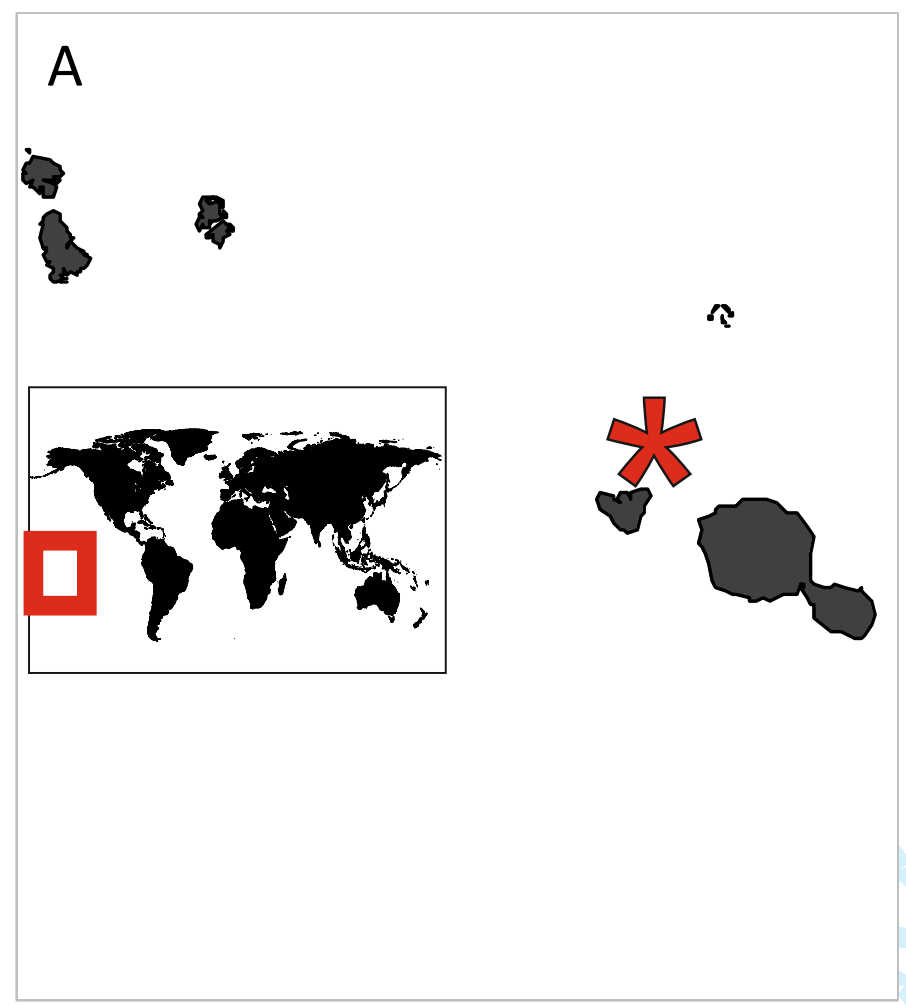

B

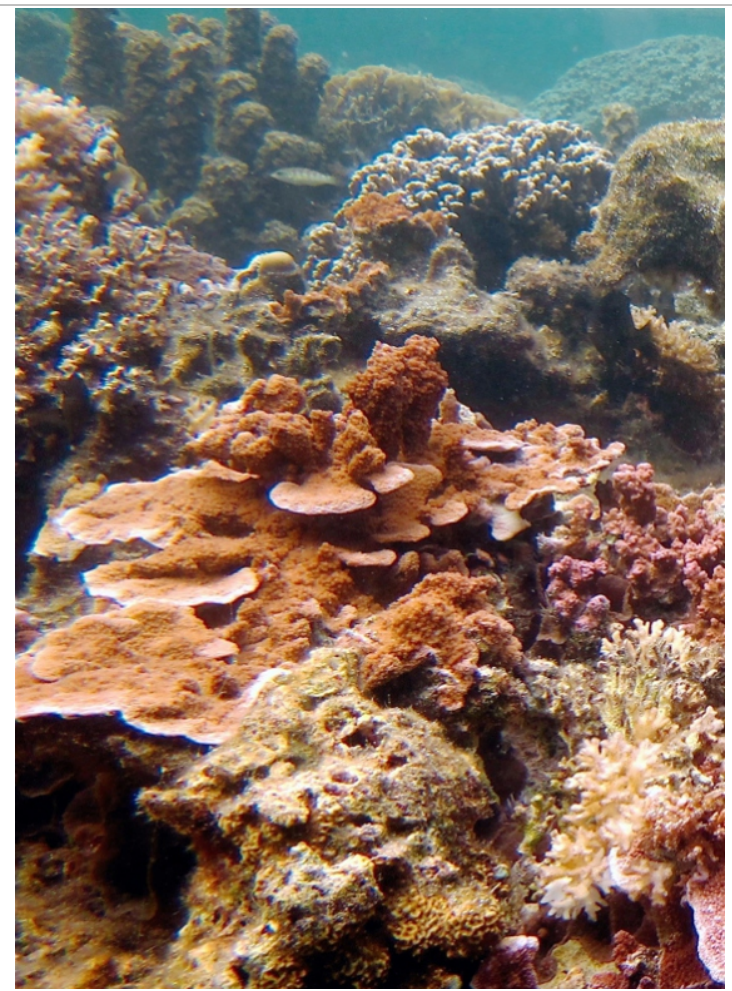

C

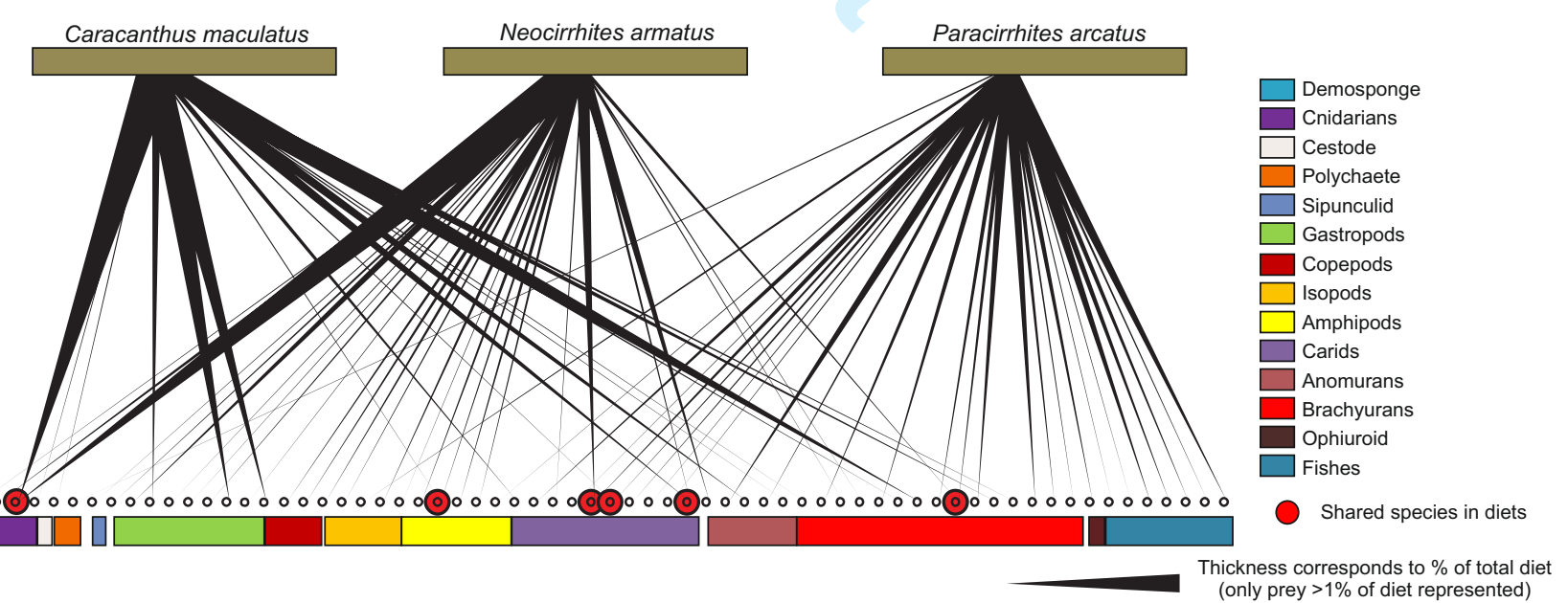


Fig. 5

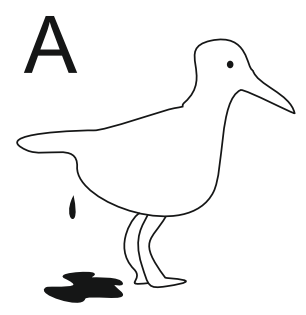

(PCR)

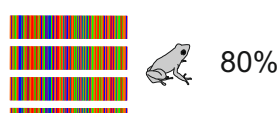

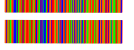

$20 \%$
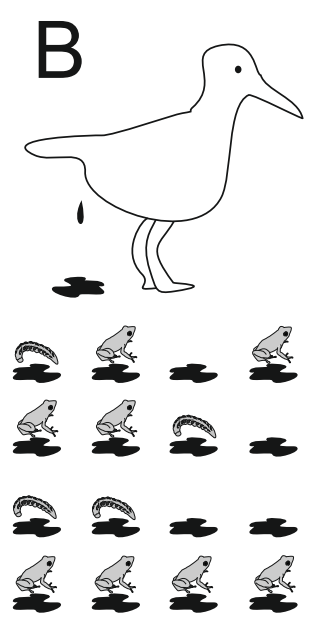

$50 \%$

จ $25 \%$
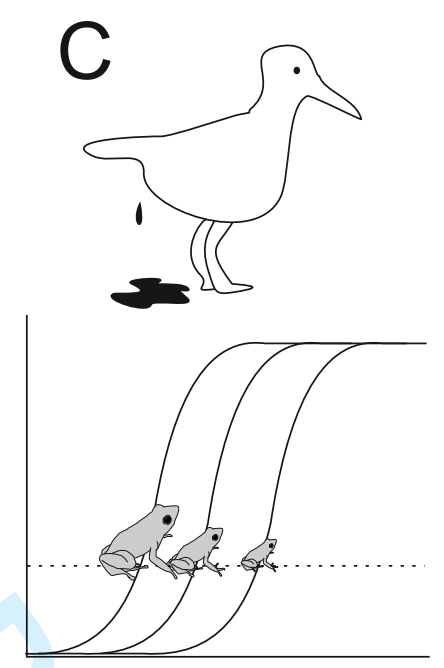

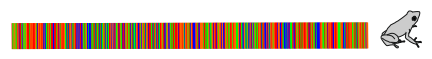

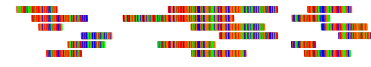

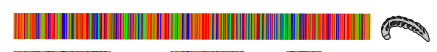

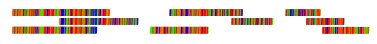

|

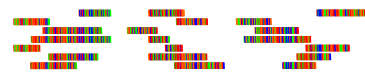

